\title{
AN EXPERIMENTAL STUDY OF THE FAHY PERMEAMETER
}

\author{
By Charles W. Burrows and Raymond L. Sanford
}

\section{CONTENTS}

Page

I. Introduction. ...................................... ${ }_{267}$

I. Purpose of this investigation........................ 267

2. The problem of magnetic measurements................ 268

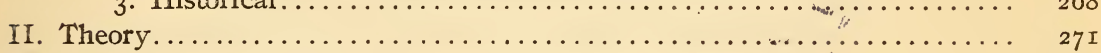

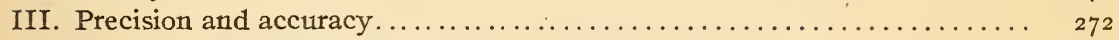

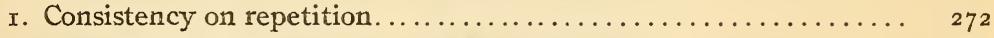

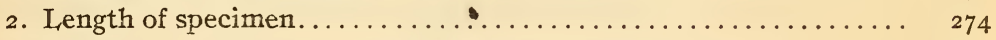

3. Projection of specimen beyond the test coil pole face......... 276

4. Reluctance of joints............................ ${ }_{27} 76$

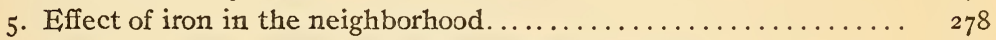

6. Position of specimen on pole face and strain effects.......... 279

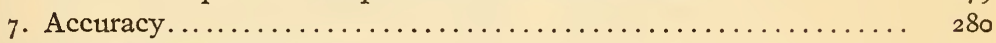

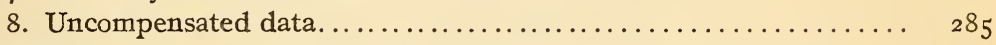

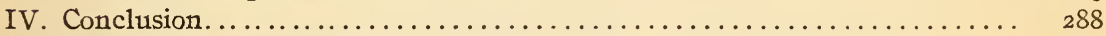

Appendix.-Description and operation of the Fahy permeameter..... 289

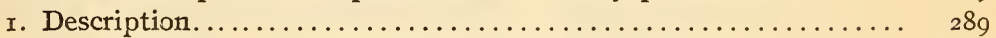

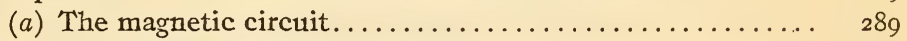

(b) Internal electrical connections...................... $29 \mathrm{I}$

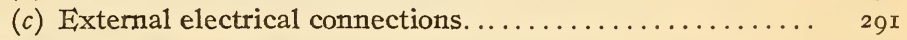

2. Calibration...................................... 293

(a) Ballistic galvanometer..................... 293

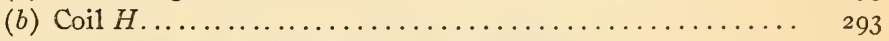

3. Determination of normal induction and hysteresis............ 294

(a) Normal induction by comparison................ 294

(b) Normal induction by absolute method.............. 295

(c) Hysteresis.............................. 295

4. Manipulation..................................... 297

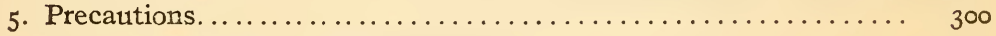

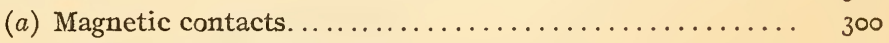

(b) Position of specimen.......................... 300

(c) External field............................ 300

\section{INTRODUCTION}

\section{PURPOSE OF THIS INVESTIGATION}

This permeameter was devised by F. P. Fahy, of the Pennsylvania Railroad Co., for the purpose of comparing the magnetic properties of two similar specimens of steel. In the fall of I9 I a cooperative investigation on the magnetic-mechanical properties 
- of steel was begun by the above-named company and the Burea:1 of Standards at the Bureau laboratories in which the Fahy apparatus was used for comparative magnetic measurements. Early results obtained with the apparatus, however, indicated the possibility of its development as a permeameter and this was immediately undertaken. In order to ascertain the degree of accuracy that has been attained, as well as its fitness for general laboratory use, a critical experimental study has been made of the instrument in its present improved form.

\section{THE PROBLEM OF MAGNETIC MEASUREMENTS}

The problem of magnetic measurements consists of the determination of simultaneous values of magnetic induction and magnetizing force. There is comparatively little difficulty in measuring the magnetic induction. . In practically all methods of any reasonable degree of accuracy the magnetic induction is measured in terms of the impulsive electromotive force induced in a test coil surrounding the specimen when the direction of the magnetic flux is reversed. This method is simple and accurate.

The difficulties of measurement center about the determination of the magnetizing force. This magnetizing force has, in general, a number of components. The principal component is due to the magnetizing current flowing through a coil of wire. This component of the magnetizing force is susceptible of calculation and for certain forms of electric and magnetic circuits the calculation is quite simple. The other components are due to magnetic poles developed in the different parts of the magnetic circuit due to joints, yokes, nonhomogeneities, etc. These components are not susceptible of calculation. They can, however, generally be measured, and in some special cases may be neutralized by means of auxiliary magnetizing coils.

\section{HISTORICAL}

The method of compensating for the effect of the yokes and joints by means of auxiliary magnetizing coils has received considerable development. Searle ${ }^{1}$ built the magnetic material into the form of a hollow square and applied the main magnetizing force through four solenoids surrounding the four sides of the square. Short coils at each corner were energized with sufficient current so that the added magnetomotive force was just equal to the magnetic potential drop due to the contact surfaces and those 
portions of the test specimens not surrounded by the main magnetizing coil. The compensating coils were in series with the main magnetizing solenoid and were adjusted once for all until a small magnetic needle placed near one of the joints showed no leakage effect. Esterline ${ }^{2}$, in his direct-reading permeameter, applied the same principle.

In the permeameter of Picou, ${ }^{3}$ compensation is effected by means of auxiliary magnetizing coils wound on each of two yokes which span the specimen. During adjustment the coils are connected so that their magnetomotive forces are in series and the flux through the yokes crosses the specimen perpendicularly at each end. With this connection the flux in the yokes is determined. Then the current in one of the coils is reversed and the main magnetizing coil which surrounds the specimen is energized, and the current in this latter coil adjusted so that the flux in the yokes is the same as before. When this adjustment has been made, the mmf of the auxiliary coils is just sufficient to overcome the reluctance of the joints and yokes, and a direct measurement of magnetizing force can be made in terms of the current in the main magnetizing coil. This apparatus gives fairly good results but is extremely tedious in operation.

The Burrows ${ }^{4}$ permeameter has a magnetic circuit consisting of two similar rods and two short yokes. Solenoids surround the rods. Small coils wound around the rods near the joints carry a current just sufficient to overcome the reluctance of the joints and yokes. This is the precision method of the Bureau of Standards and has been officially adopted as the standard method by the American Society for Testing Materials.

Ewing ${ }^{5}$ attempted to eliminate the effect of the reluctance of the yokes and joints by experimental means. His magnetic circuit consists of two bars and two yokes as in the Burrows permeameter. Magnetic measurements are made first with short magnetizing coils and the yokes close up to them, then with double the length of coil. The additional magnetomotive force required to magnetize this second system is theoreticaliy just sufficient to overcome the reluctance of the extra length of specimen. This method assumes several conditions which are not met. The leakage at the yokes is not zero nor is it the same in the two

2 Treat and Esterline, Magnetic Testing Apparatus, E1. World, 30, pp. 696-697; 897 .

${ }^{3}$ Picou, Permeancter Universel, Bull. soc. internat. d'electr., 2, pp. 828-834; 1902 .

${ }^{1}$ Burrows, this Bulletin, 6, pp. $3^{\mathrm{I}-88}$ (Scientific Paper No. II7), 1909; see also Magnetic Testingy Circular No. I 7 of the Burcau of Standards.

${ }^{5}$ Ewing, Magnetic Induction in Irou and Other Metals, p. 362; I900. 
systems. Further, it is difficult to secure two test specimens which are uniform throughout their length and equivalent magnetically to each other. The authors of the present paper have been trying unsuccessfully for a number of years to get two rather long rods which were magnetically uniform along their length for the purpose of trying out this method with several widely different lengths. Our work, however, shows that with uniform material the Ewing method would give fairly good results.

The joint reluctance may be determined experimentally once for all by means of measurements in a given apparatus of a standard bar whose true magnetic constants have been determined in some other way. This is the procedure of the Physikalisch-TechnischeReichsanstalt, where a massive iron yoke is used to bridge the ends of the test specimen. The apparatus is calibrated in terms of the values obtained on an ellipsoid of revolution first measured magnetometrically and later machined down to a cylinder.

The last method mentioned consists in the measurement of the difference of magnetic potential between the ends of a test specimen. Provided there is no source of $\mathrm{mmf}$ between the ends of the specimen, this magnetic potential difference is the total $\mathrm{mmf}$ required to maintain the flux in the specimen. If there is such a source of mmf, then the potential difference measured between its ends is the algebraic sum of the impressed $\mathrm{mmf}$ and the drop in the specimen.

A number of investigators have used this method of potential difference in magnetic measurements.

Chattock ${ }^{\circ}$ described a method which he calls a "magnetic potentiometer," showing theoretically that the difference of magnetic potential between two points can be measured by means of a uniformly wound test coil of constant cross section.

Later Rogowski and Steinhaus ${ }^{7}$ described the same method of measurement and gave the results of a number of experiments made with the apparatus. Goldschmidt ${ }^{8}$ has described a method using a yoke having a gap with a magnetic needle in it similar to the arrangement of the well-known Ewing permeability bridge. On this yoke is a winding with which a mmf is produced opposing that to be measured. When the needle indicates a balance the mmf in ampere turns is equal to the product of current and turns in this winding. Iliovici ${ }^{9}$ has described a permeameter in which

- Chattock, Phil. Mag., 24, p. 94; 1857.

${ }^{2}$ Rogowski and Steinhaus, Archiv für Elektrotechnick, 1, p. 14r; 1912.

${ }^{8}$ Goldschmidt, Electrician, 54, p. 207; 1904.

${ }^{2}$ Iliovici, Bull. Soc. Int. des Elec. ${ }_{3}$ d ser., 3, p. 58r; r9r3. 
he uses a yoke with a test coil wound on it to detect a difference of magnetic potential. In this apparatus compensation is made for yokes and joints which is indicated by zero potential between the ends of the specimen. Goltze ${ }^{10}$ published data giving the results of permeability tests on a number of specimens magnetized between the poles of an electromagnet. He used an arrangement of the form described by Chattock and Rogowski and Steinhaus for the determination of magnetizing force.

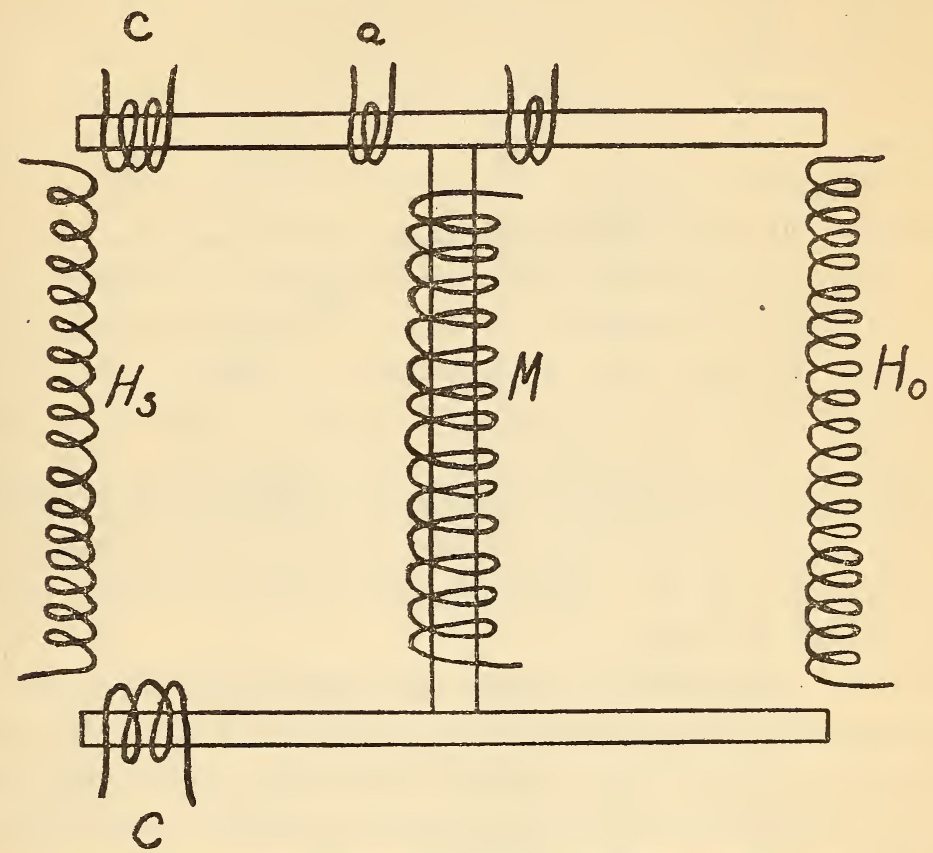

FIG. 2.-Magnetic and electrical circuits in their simplest form

The Fahy permeameter, which is the subject of the present paper, utilizes this latter principle. A short description of the apparatus has already been published. ${ }^{11}$

\section{THEORY}

The basis of operation of this instrument is apparent from a consideration of Fig. 2, which shows the circuits of the instrument in their simplest form. The apparatus is $\mathrm{H}$-shaped, with two test coils, $H_{\mathrm{o}}$ and $H_{\mathrm{s}}$, spanning the free ends of the $H$ and a magnetizing coil, $M$, wound on the crosspiece of the $H$.

By reason of the symmetry of the two parallel magnetic circuits thus formed it is evident that the magnetizing coil produces the 
same amount of flux in the two equal coils $H_{\mathrm{o}}$ and $H_{\mathrm{s}}$ and that either one may be used to measure the mmf drop between the yokes, and from this value the mean magnetizing force may be calculated.

If now we span the yokes by a steel bar placed within the coil $H_{\mathrm{B}}$, the above conditions do not hold exactly. The $H_{\mathrm{o}}$ coil still measures the mmf drop between the pole faces which it spans. This drop, however, is not equal to the drop between the other pole faces. Due to the increased flux density in the yokes adjacent to the specimen, a greater proportion of the $\mathrm{mmf}$ is used to force the greater flux through one set of yokes than through the other set. Consequently, since the available $\mathrm{mmfs}$ in the two paraliel magnet circuits are equal, the potential difference caught by the coil $H_{\mathrm{s}}$ is less than that caught by the coil $H_{\mathrm{o}}$.

The magnetic potential differences between the ends of the coils can be reduced to equality by means of compensating coils, $C$, wound on the yokes near the pole faces. The criterion of proper adjustment for this compensating $\mathrm{mmf}$ is equality of leakage through the air on the two sides of the apparatus. The leakage on each side is measured by means of a short coil, $a$, wound on the yoke near the core and connected differentially in series with the main test coil $H_{\mathrm{s}}$. The two test coils, of course, have the same number of turns.

After the adjustment is made the magnetizing force and magnetic induction may be measured in terms of the emfs induced in the coils $H_{\mathrm{o}}$ and $H_{\mathrm{s}}$ on reversal of the main magnetizing current.

A full description of the apparatus and detailed instructions for the manipulation are given in the appendix.

\section{PRECISION AND ACCURACY}

An experimental study of the permeameter has been made with a view to determining its precision, and also of the individual factors which might affect the accuracy of measurements such as variations in contact reluctance, length of specimen, position of specimen on pole face, etc.

\section{CONSISTENCY ON REPETITION}

Any measuring instrument to be of value must be capable of giving concordant results from repeated tests of the same specimen. It is essential, therefore, that all the factors which might 
affect the accuracy of the measurements shall have so small an influence on the results as to be of negligible importance.

The ability of this apparatus to repeat readings on the same specimen under the same conditions is all that could be desired. This is shown very clearly by Fig. 3, where the solid curve represents a first determination and the circles represent points taken on the same bar after it had been removed from the apparatus

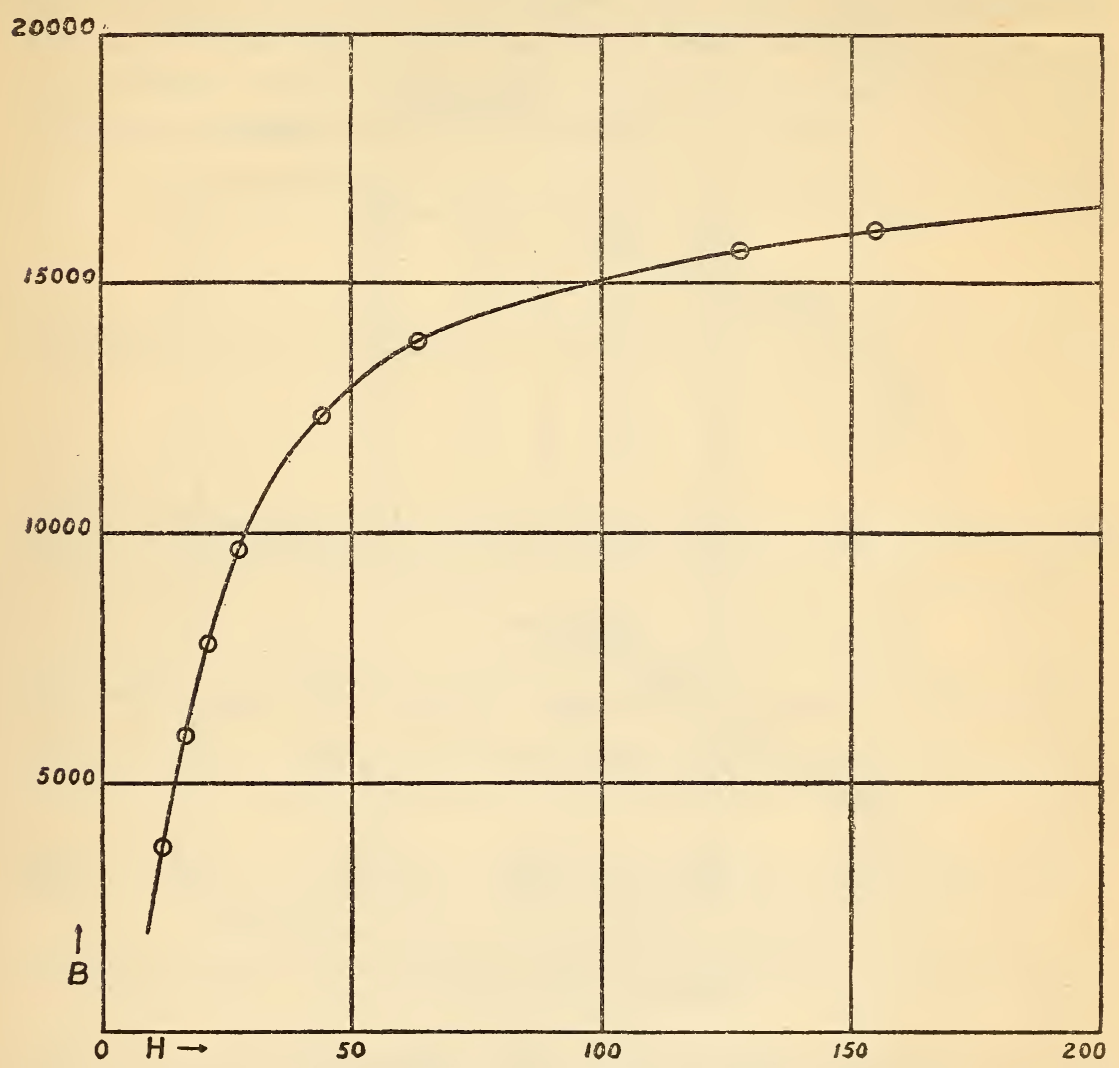

FIG. 3.-Showing consistency on repetition

The solid curve represents a first determination and the circles represent points taken after removal of the specimen and reinsertion.

and reinserted. The consistency is so good that this apparatus may be used to detect small changes in magnetic characteristics due to aging, mechanical strains, or differences due to small variations in heat treatment. The limit of consistency on repetition is probably determined by the reliability of the ballistic galvanometer and its ability to give the same deflection under the influence of the same impulse. 


\section{LENGTH OF SPECIMEN}

This apparatus is designed to take specimens of a fixed length. The particular piece of apparatus under investigation was designed for a specimen $25.4 \mathrm{~cm}$ long. However, it frequently happens that it is necessary to test other lengths. Sometimes one wishes to know the magnetic characteristics of a portion of a long bar without cutting the bar. With this in view the end of a long bar was measured once with the whole bar intact and the free end projecting beyond the back pole face, and again with the excess portion of the bar removed. In each case the same material was between the pole faces, and one end of the test specimen was flush

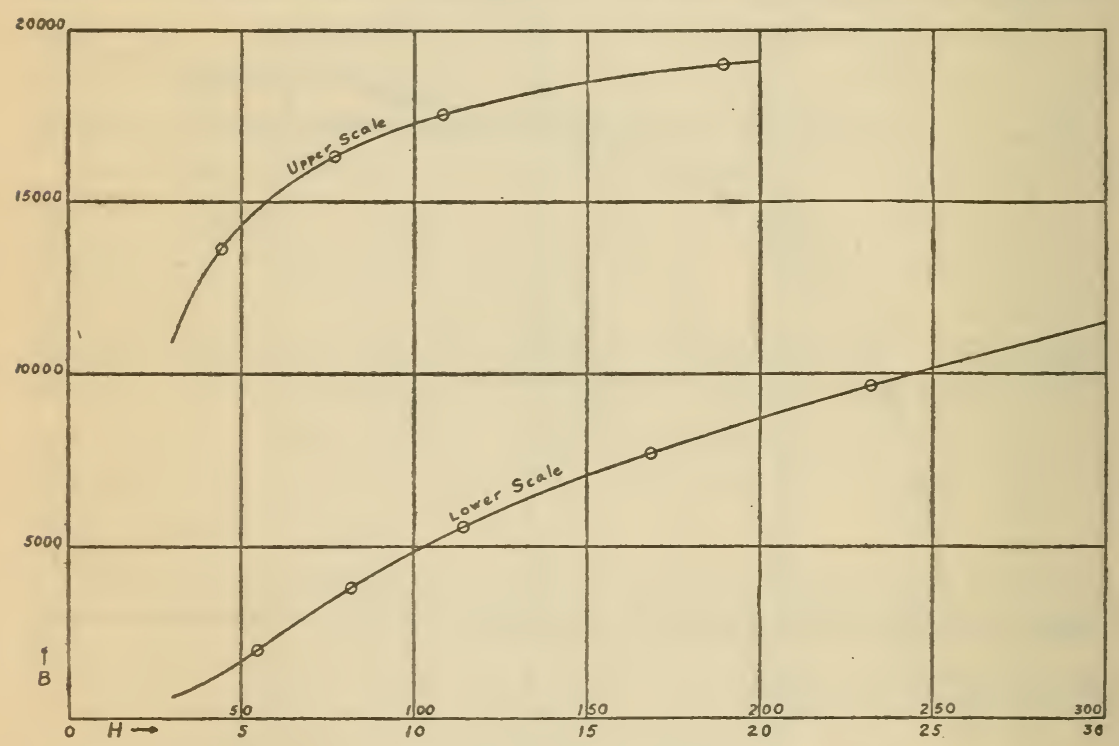

FIG. 4.-Showing the effect of projection of a long specimen

The solid curve shows normal induction for a specimen of proper length and the circles represent points taken with a projection of $150 \mathrm{~cm}$.

with the test-coil pole faces. In Fig. 4 the solid curve shows the normal induction of the specimen cut to length, and the circles show points determined with a projection of $150 \mathrm{~cm}$ or six times the length of the specimen. The points fall very nearly upon the curve. It is difficult to tell whether the small difference is a real variation due to the projection or to a strain set up in the specimen by the weight of the projecting end. To reduce this latter the free end was supported.

As a check on the preceding, and also to make sure that this particular length is not a critical length at which several errors balance each other, a second bar was measured at one particular magnetizing force, after the bar had been reduced in length by 
successive steps. In each case the same portion of material was tested, and the end of the test specimen was kept flush with the test-coil pole face. Table I shows the values of induction obtained with different lengths of the test sample projecting beyond the pole face. These results are for a magnetizing force of 58 gausses.

TABLE 1

Values of Induction Obtained for a Magnetizing Force of 58 Gausses with Different Lengths of the Test Sample Projecting Beyond the Pole Face

\begin{tabular}{|c|c|}
\hline $\begin{array}{c}\text { Projection in } \\
\text { centimeters }\end{array}$ & Induction \\
\hline 125 & 15140 \\
25 & 15120 \\
10 & 15130 \\
5 & 15210 \\
2 & 15210 \\
0 & 15190 \\
-1 & 15210 \\
-2 & 15230 \\
-3 & 14580 \\
\hline
\end{tabular}

Here, again, it is not safe to say that there is any influence of the projecting end that may not be accounted for by strain in the material rather than by the mere presence of the ends. As the bar is reduced further in length so that it is less than the normal length, no appreciable change takes place until the reduction amounts to $3 \mathrm{~cm}$. Since the full pole face width is $4 \mathrm{~cm}$, this means a reduction in contact surface to one-fourth the normal amount. This reduces the induction by 600 in 15000 , or 4 per cent. This difference is removed when measurements are taken with this shortened test specimen placed not with one end flush with the test coil pole face, but symmetrically between the two pole faces. In this latter position the induction was 15 I 70 , which is in good agreement with the normal length value of 15 I 90 gausses.

From the above it is quite evident that no appreciable error is introduced by the projecting end of the test specimen, provided this projection extends beyond the back yoke of the apparatus. Extension beyond the test coil pole face may be expected to introduce considerable error unless care is taken to compensate for the effects of this projection. This compensation is taken care of automatically by placing a test coil over the projecting end of the specimen close to the yoke and a similar coil in the corresponding place over the other end of the same yoke. Each of these test coils is connected in series with the other test coils on the same side of the core, and adjustments are made in the usual way. 


\section{PROJECTION OF SPECIMEN BEYOND THE TEST COL POLE FACE}

One factor that might affect the accuracy of measurements is improper insertion of the test piece so that one end projects beyond the test coil pole face. A test was made to determine the degree of accuracy with which the end of the specimen must be lined up with the edge of the test coil pole face. A test piece of the proper length was clamped with different amounts of projection beyond the pole face and the inductions read with three different values of magnetizing force. The results are given in Table 2 .

TABLE 2

Observed Inductions with Various Projections Beyond Test Coil Pole Face

\begin{tabular}{|c|c|c|c|}
\hline & \multicolumn{3}{|c|}{ Magnetizing force } \\
\cline { 2 - 4 } $\begin{array}{c}\text { Projection in } \\
\text { millimeters }\end{array}$ & 10.5 & 23.5 & 54.0 \\
\cline { 2 - 4 } & & & \\
\cline { 2 - 4 } 6 & 5080 & 9740 & 14770 \\
4 & 5080 & 9770 & 14780 \\
2 & 5090 & 9790 & 14800 \\
0 & 5090 & 9800 & 14810 \\
-2 & 5110 & 9800 & 14820 \\
-4 & 5120 & 9800 & 14820 \\
-6 & 5150 & 9810 & 14840 \\
\hline
\end{tabular}

The effect is so slight that extreme care in lining up the specimen is not necessary. It is very easy to line up a bar to within I mm of the edge, so that no trouble is to be expected from this source.

\section{RELUCTANCE OF JOINTS}

It is to be expected that in apparatus of this type the reluctance of the surface of contact will affect the accuracy. To get some idea of the magnitude of the influence of the joint reluctance, measurements were made with paper inserted between the specimen and the pole faces. In Fig. 5, curves $A, B$, and $D$ show the variation in induction with the width of gap for several magnetizing forces. The greatest effect of the gap seems to be in the region of maximum permeability as shown by curve $B$. These curves are of interest, since they show the effect of different width of gap. However, in actual practice there is no such air gap. Imperfect contact is due either to the warping of the specimens so that they do not seat well upon the pole faces or to the presence of scale. To approximate this latter condition thin sheet transformer iron was interposed between the specimen and pole faces. Curve $C$ 
shows the effect of one and of two such sheets upon the measured values of the induction in a region where a large effect was found for the paper separators.

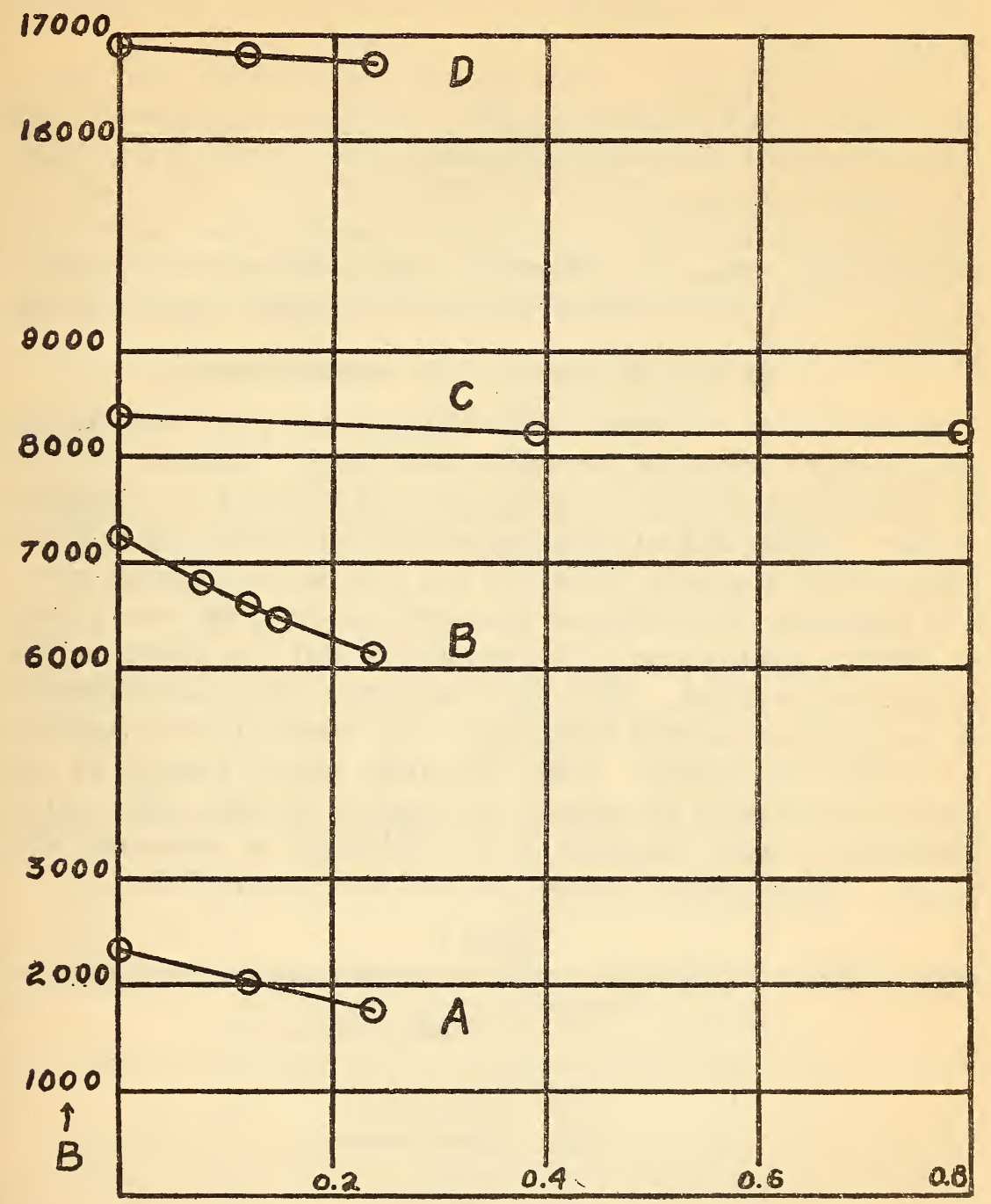

\section{Thickness of Separating Material (mm)}

FIG. 5.-Showing the effect of added reluctance at the pole contacts

In curves $A, B$, and $D$ the extra reluctance is due to paper inserted between the specimen and the pole face. In curve $C$ the separating material is oxidized sheet steel

This transformer material as measured with a parallel-face micrometer had a thickness of $0.385 \mathrm{~mm}$. Calculations based upon measured values of the mass, density, length, and breadth gave a mean thickness of $0.364 \mathrm{~mm}$. This difference of $0.02 \mathrm{r}$, $59467^{\circ}-18-8$ 
or 5.8 per cent, is due to the irregularities of the surface. If we assume that the high permeability transformer steel adds only a negligible amount to the contact reluctance, the total added reluctance is due to the irregularity of surface and to the less magnetic coating of scale.

The paper separators undoubtedly cause a greater joint reluctance than would occur in practice. The close agreement in the comparison with the Burrows permeameter, in which this joint reluctance is compensated for, is evidence that the joint reluctance when the specimen alone is in place does not give rise to any serious error. However, the above results show that in precision work it is desirable to have fairly good magnetic contact at the pole faces.

\section{EFFECT OF IRON IN THE NEIGHBORHOOD}

Pieces of iron in contact with the test coil pole faces during measurement will cause an appreciable error. However, such a situation could arise only intentionally and need not be considered further. Pieces of iron placed otherwise than in very close proximity to the magnetic circuit do not produce any serious error. Ten kilograms of transformer steel strips 50 by $3 \mathrm{~cm}$ were placed in various positions near the apparatus and the effect on the measurements noted. With the transformer strips placed parallel to the yokes and as near to the side of the wooden base as possible, no result was noticed. With the strips placed parallel to the specimen and close up against the case on the same side as the specimen, a small decrease in the induction as measured was noted. The numerical values observed are given in Table 3 .

TABLE 3

Effect of a Mass of Transformer Iron Placed Near the Permeameter on the Observations

\begin{tabular}{|c|c|c|}
\hline HI & B & Position of iron strips \\
\hline \multirow[t]{3}{*}{27.6} & 11040 & Removed. \\
\hline & 11040 & Parallel to yoke. \\
\hline & 10955 & Parallel to specimen. \\
\hline \multirow[t]{2}{*}{73.5} & 16610 & Removed. \\
\hline & 16540 & Parallel to yoke. \\
\hline \multirow[t]{2}{*}{157} & 19360 & Removed. \\
\hline & 19340 & Parallel to specimen. \\
\hline
\end{tabular}

Even when a bar of iron is placed directly against the back yoke the effect is not very great, as is shown by the following data. The disturbing bar was $150 \mathrm{~cm}$ long and of the same cross section ( $\mathrm{I}$ by $\mathrm{I} \mathrm{cm}$ ) as the test specimen. The magnetic measurements were made at a magnetizing force of 56.2 gausses. The results are shown in Table 4 . 
TABLE 4

Inductions of a Test Specimen With a Second Rod $150 \mathrm{~cm}$ Long Placed in Various Positions

\begin{tabular}{|c|l|}
\hline Induction & \multicolumn{1}{|c|}{ Position of second rod } \\
\cline { 2 - 2 } 15285 & Removed. \\
15260 & Butting against test specimen. \\
15195 & Lapping pole face by $1 \mathrm{~cm}$. \\
15210 & Lapping pole face by $3 \mathrm{~cm}$. \\
\hline
\end{tabular}

The general effect of this disturbing bar is very slight and is always in the direction of a diminished induction.

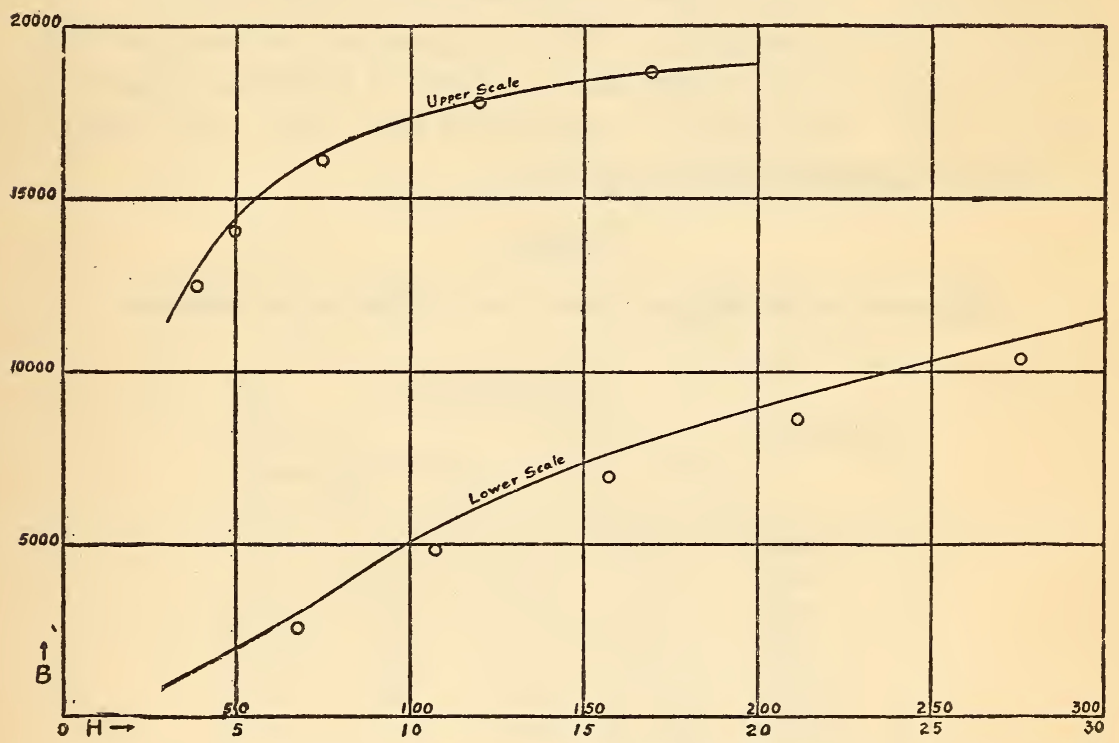

FIG. 6.-Showing the effect of strain in the specimen

The solid curve shows normal induction when specimen is free from strain and the circles represent points taken with the specimen slightly distorted

In general, it is safe to say that all masses of iron at distances from the permeameter greater than a few inches are without any appreciable effect.

\section{POSITION OF SPECIMEN ON POLE FACE AND STRAIN EFFECTS}

A very interesting point was brought out in an attempt to discover whether the exact position of the specimen on the pole face made any difference. With this in view, measurements were made with the specimen seated symmetrically on the pole faces and with the specimen making contacts on the lower portions of the pole faces. The results first obtained are shown in Fig. 6. 
For these measurements the specimen was held in place by the clamps only. When the specimen was held against the middle portions of the pole pieces the clamps acted normally. However, with the specimen making contact on the lower portions of the pole faces the pressure exerted by the clamps was concentrated on one edge of the specimen. This lack of symmetrical pressure coupled with a slight warp causes a strain in the specimen. This strain is accompanied by a change in magnetic properties as indicated by Fig. 6 . In order to make sure that this difference was due to strains in the test piece, the clamping device was so modified that it exerted a normal pressure for each position of the test specimen. These latter conditions gave substantially identical results for all positions of the test specimen on the pole faces.

Table 5 gives further data on the effects of strain in a specimen. The specimen was slightly warped and the strain was produced by tightly clamping in the apparatus.

TABLE 5

Differences in the Magnetic Data Due to Strain in the Specimen

\begin{tabular}{|r|c|c|c|c|}
\hline \multirow{3}{*}{ Induction } & \multicolumn{4}{|c|}{ Magnetizing force } \\
\cline { 2 - 6 } & Strain & No strain & Difference & $\begin{array}{c}\text { Per cent } \\
\text { difference }\end{array}$ \\
\hline & & & & \\
\hline 2000 & 1.62 & 1.58 & 0.04 & 2.5 \\
4000 & 2.39 & 2.24 & .15 & 6.7 \\
6000 & 3.21 & 2.97 & .24 & 8.1 \\
8000 & 4.21 & 3.88 & .33 & 8.5 \\
10000 & 5.63 & 5.13 & .50 & 9.8 \\
12000 & 7.74 & 7.09 & .65 & 9.2 \\
14000 & 12.1 & 11.8 & .3 & 2.5 \\
16000 & 29.6 & 29.6 & 0 & 0 \\
18000 & 108. & 112. & -4. & -3.6 \\
\hline
\end{tabular}

The effect of strain may be either an increase or a decrease in permeability. Whether the change in permeability is an increase or decrease depends in all probability upon whether the tension or compression along the length of the specimen predominates. The observed differences can not be due entirely to an improvement in magnetic contact because the strained material shows a lower permeability in spite of the improved contact conditions.

\section{ACCURACY}

In order to determine the absolute accuracy of the measurements taken by this permeameter a number of bars were measured 
in both the Burrows and the Fahy permeameters. The test rods for this investigation were taken from the magnetic standards of the Bureau. These standards have been carefully prepared and aged. They have been examined for magnetic uniformity and are the best magnetic standards at present obtainable.

The magnetic characteristics are shown in Figs. 7 and 8 . It is to be noticed how completely these bars cover the full range of magnetic possibilities.

Tables 6 to 12 give the numerical values of the normal induction both by the Burrows permeameter and the permeameter under examination. These measurements for the seven materials

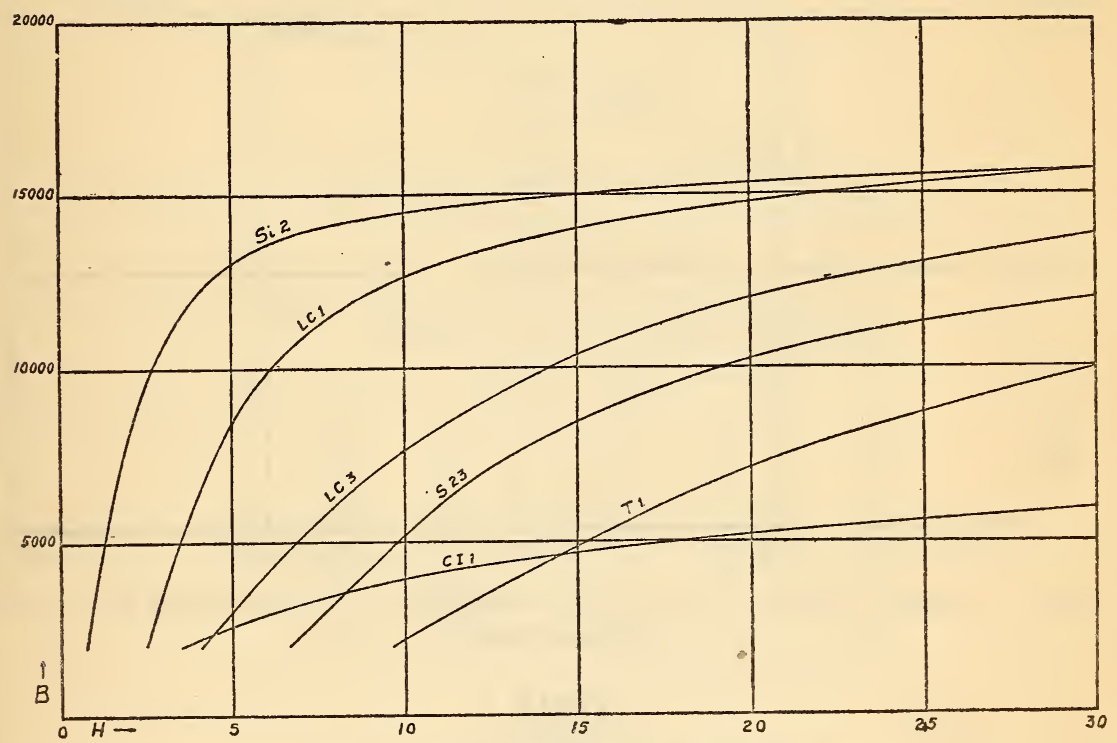

FIG. 7.-Normal induction curves for the standard bars for magnetizing forces up to 30 gausses

are in every case within 5 per cent of the true value. Such accuracy is all that is required by most commercial needs. In fact it is greater than one is justified in seeking in the case of many materials. The truth of this statement is evident when one considers that many materials differ from region to region by more than this amount. For example, the permeability of transformer steel differs from part to part even in a single sheet by as much as ro per cent or 20 per cent. Rods which have not been prepared with especial reference to securing uniformity may show differences in permeability along their length of as much as Io per cent or more. 


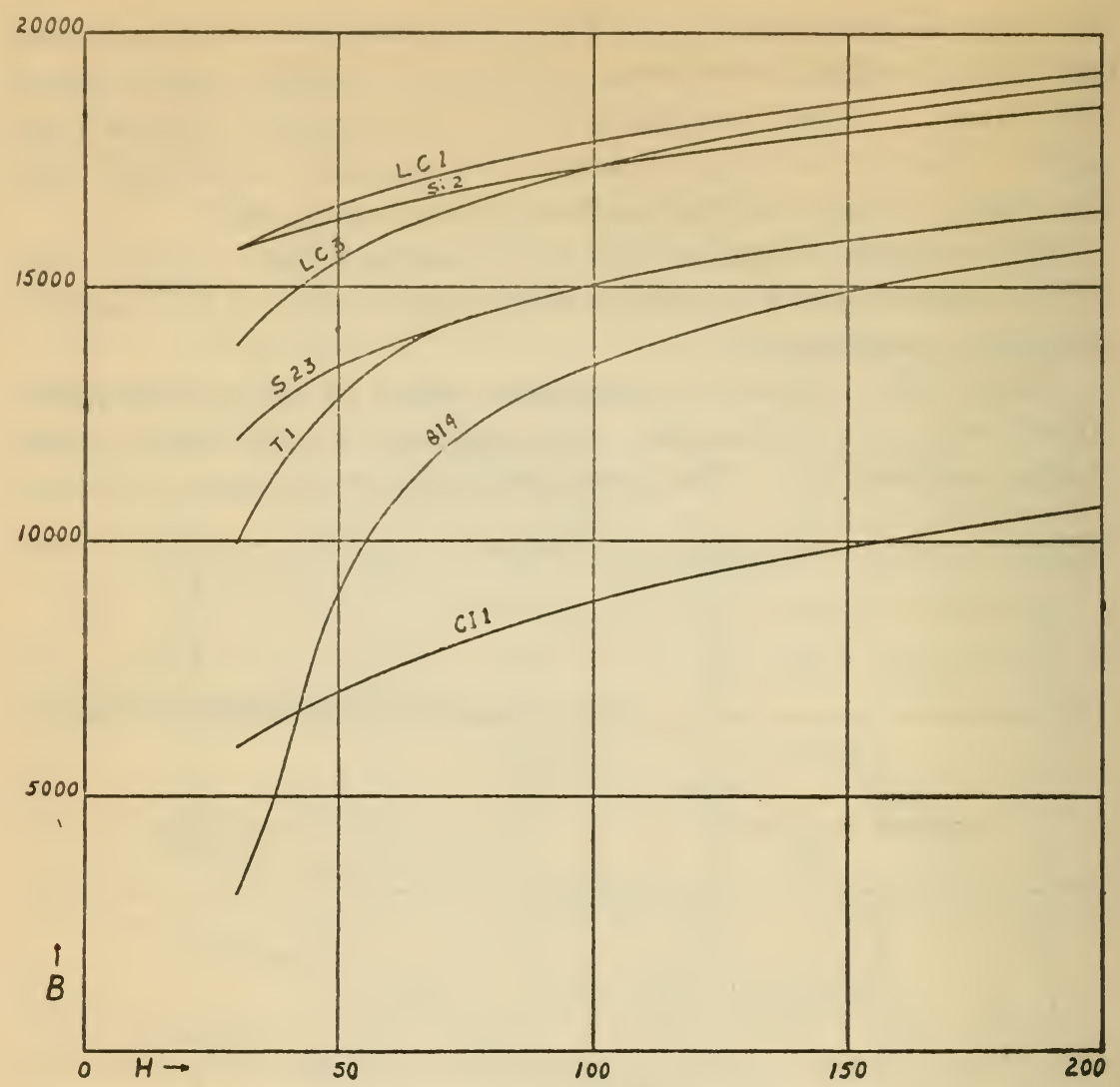

FIG. 8.-Normal induction curves for the standard bars for magnetizing forces from 30 to 200 gausses

\section{TABLE 6}

Bar LC1, Machinery Steel, $1.27 \mathrm{~cm}$ Diameter

\begin{tabular}{|r|r|r|r|r|}
\hline & \multicolumn{4}{|c|}{ Magnetizing force } \\
\cline { 2 - 5 } Induction & Standard & Fahy & Difference & $\begin{array}{r}\text { Per cent } \\
\text { difference }\end{array}$ \\
\hline & & & & \\
\hline 2000 & 2.49 & 2.37 & 0.12 & 4.8 \\
4000 & 3.15 & 3.12 & .03 & 1.0 \\
6000 & 3.82 & 3.91 & -.09 & -2.4 \\
8000 & 4.72 & 4.91 & -.19 & -4.0 \\
10000 & 6.10 & 6.40 & -.30 & -4.9 \\
12000 & 8.61 & 8.96 & -.35 & -4.1 \\
14000 & 14.8 & 15.0 & -.02 & -1.4 \\
16000 & 35.0 & 34.0 & 1.0 & 2.9 \\
18000 & 106. & 102. & 4. & 3.8 \\
& & & & \\
\hline
\end{tabular}


TABLE 7

Bar LC3, Machinery Steel, $1.27 \mathrm{~cm}$ Diameter

\begin{tabular}{|c|c|c|c|c|}
\hline \multirow{2}{*}{ Induction } & \multicolumn{4}{|c|}{ Magnetizing force } \\
\hline & Standard & Fahy & Difference & $\begin{array}{l}\text { Per cent } \\
\text { difference }\end{array}$ \\
\hline 2000 & 4.08 & 4.07 & 0.01 & 0.2 \\
\hline 4000 & 5.88 & 5.78 & .10 & 1.7 \\
\hline 6000 & 7.88 & 7.81 & .07 & .9 \\
\hline 8000 & 10.5 & 10.3 & .2 & 1.9 \\
\hline 10000 & 14.1 & 14.0 & .1 & .7 \\
\hline 12000 & 20.0 & 19.7 & .3 & 1.5 \\
\hline 14000 & 31.3 & 30.9 & .4 & 1.3 \\
\hline 16000 & 58.3 & 57.4 & .9 & 1.5 \\
\hline 18000 & 127. & 123. & 4. & 3.2 \\
\hline
\end{tabular}

TABLE 8

Bar T1, Tool Steel, $1.27 \mathrm{~cm}$ Diameter

\begin{tabular}{|r|c|c|c|c|}
\hline & \multicolumn{4}{|c|}{ Magnetizing force } \\
\cline { 2 - 5 } Induction & Standard & Fahy & Difference & $\begin{array}{c}\text { Per cent } \\
\text { difference }\end{array}$ \\
\hline & & & & \\
\hline 2000 & 9.60 & 9.27 & 0.33 & 3.4 \\
4000 & 13.3 & 13.0 & .3 & 2.3 \\
6000 & 17.3 & 16.9 & .4 & 2.3 \\
8000 & 22.5 & 21.6 & .9 & 4.0 \\
10000 & 30.1 & 29.0 & 1.1 & 3.7 \\
12000 & 42.4 & 41.2 & 1.2 & 2.8 \\
14000 & 68.5 & 66.7 & 1.8 & 2.6 \\
16000 & 156. & 150. & 6. & 3.8 \\
\hline
\end{tabular}

TABLE 9

Bar Si2, Silicon Steel, $1.27 \mathrm{~cm}$ Diameter

\begin{tabular}{|r|r|r|r|r|}
\hline & \multicolumn{4}{|c|}{ Magnetizing torce } \\
\cline { 2 - 5 } & Standard & Fahy & Difference & $\begin{array}{c}\text { Per cent } \\
\text { difference }\end{array}$ \\
\hline 2000 & 0.76 & 0.74 & 0.02 & 2.6 \\
4000 & 1.11 & 1.13 & -.02 & -1.8 \\
6000 & 1.49 & 1.47 & .02 & 1.3 \\
8000 & 2.00 & 1.99 & .01 & .5 \\
10000 & 2.67 & 2.75 & -.08 & -3.0 \\
12000 & 3.81 & 3.99 & -.18 & -4.7 \\
14000 & 7.20 & 7.21 & -.01 & -.1 \\
16000 & 39.0 & 37.8 & 1.2 & 3.1 \\
18000 & 146. & 140. & 6. & 4.1 \\
\hline
\end{tabular}


TABLE 10

Bar S23, 1 Per Cent Carbon Steel, 2.97 by $0.886 \mathrm{~cm}$

\begin{tabular}{|r|r|r|r|r|}
\hline & \multicolumn{4}{|c|}{ Magnetizing force } \\
\cline { 2 - 5 } Induction & Standard & Fahy & Difference & $\begin{array}{c}\text { Per cent } \\
\text { difference }\end{array}$ \\
\cline { 3 - 5 } & & & & -1.5 \\
2000 & 6.60 & 6.70 & -0.10 & -3.4 \\
4000 & 8.74 & 9.04 & -.30 & -3.4 \\
6000 & 10.9 & 11.3 & -.4 & -3.7 \\
8000 & 14.0 & 14.5 & -.5 & -3.6 \\
10000 & 19.1 & 19.9 & -.8 & -4.2 \\
12000 & 30.0 & 31.0 & -1.0 & -3.3 \\
14000 & 63.5 & 63.1 & .4 & .6 \\
16000 & 156. & 162. & -6. & -3.8 \\
\hline
\end{tabular}

TABLE 11

Bar 614, Tungsten Steel, 2.97 by $0.966 \mathrm{~cm}$

\begin{tabular}{|r|r|r|r|r|}
\hline & \multicolumn{4}{|c|}{ Magnetizing force } \\
\cline { 2 - 5 } Induction & Standard & Fahy & Difference & $\begin{array}{r}\text { Per cent } \\
\text { difference }\end{array}$ \\
\cline { 2 - 5 } 2000 & 22.9 & 22.8 & 0.1 & 0.4 \\
4000 & 34.0 & 34.8 & -.8 & -2.4 \\
6000 & 40.2 & 41.4 & -1.2 & -3.0 \\
8000 & 46.0 & 47.9 & -1.9 & -4.1 \\
10000 & 54.8 & 57.5 & -2.7 & -4.9 \\
12000 & 72.2 & 75.2 & -3.0 & -4.2 \\
14000 & 114. & 117. & -3. & -2.6 \\
15000 & 153. & 160. & -7. & -4.6 \\
\hline
\end{tabular}

TABLE 12

Bar CIl, Cast Iron, 3.00 by $0.950 \mathrm{~cm}$

\begin{tabular}{|r|c|c|c|c|}
\hline & \multicolumn{4}{|c|}{ Magnetizing force } \\
\cline { 2 - 5 } Induction & Standard & Fahy & Difference & $\begin{array}{c}\text { Per cent } \\
\text { difference }\end{array}$ \\
\hline & & & & \\
\hline 2000 & 3.50 & 3.61 & -0.11 & -3.1 \\
4000 & 10.2 & 10.7 & -0.5 & -4.9 \\
6000 & 30.0 & 31.1 & -1.1 & -3.7 \\
8000 & 73.0 & 76.0 & -3.0 & -4.1 \\
10000 & 153. & 156. & -3. & -2.0 \\
\hline
\end{tabular}


TABLE 13

Comparison of Hysteresis Values with Standard Data

\begin{tabular}{|c|c|c|c|c|c|}
\hline Bar & Method & $\mathbf{H}_{\max }$ & $\mathbf{B}_{\max }$ & $\mathbf{B}_{\mathbf{r}}$ & $\mathbf{H}_{\mathbf{c}}$ \\
\hline \multirow{3}{*}{ LC1.. } & [Standard. & 150 & 18620 & 12200 & 2.9 \\
\hline & $\{$ Fahy ............... & 150 & 18760 & 12120 & 2.8 \\
\hline & jStandard......................... & 150 & 18320 & 7150 & 4.8 \\
\hline LC3. & $\{$ Fahy................ & 150 & 18460 & 7580 & 5.3 \\
\hline \multirow{2}{*}{$\mathbf{T} 1 \ldots \ldots \ldots \ldots \ldots$} & 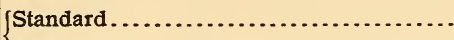 & 150 & 15950 & 9650 & 12.6 \\
\hline & $\{$ Fahy $\ldots \ldots \ldots \ldots \ldots \ldots$ & 150 & 16000 & 9610 & 12.7 \\
\hline \multirow{2}{*}{ S23.. } & $\{$ Standard........................ & 150 & 15920 & (........... & 9.4 \\
\hline & 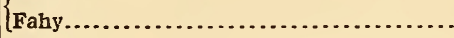 & 150 & 15840 & 10630 & 9.8 \\
\hline \multirow{2}{*}{$614 \ldots$} & $\int$ Standard .............. & 150 & 14930 & 10220 & 39.3 \\
\hline & $\{$ Fahy..................................... & 150 & 14780 & 9950 & 39.3 \\
\hline \multirow{2}{*}{ CI1... } & fStandard................................ & 154.5 & 10000 & 2800 & 2.8 \\
\hline & $\{$ Fahy $\ldots \ldots \ldots \ldots \ldots \ldots \ldots \ldots \ldots$ & 156.0 & 10000 & 3000 & 2.8 \\
\hline
\end{tabular}

Table $\mathrm{I} 3$ shows a similar set of data on residual induction $\left(\mathrm{B}_{\mathrm{r}}\right)$ and coercive force $\left(\mathrm{H}_{\mathrm{c}}\right)$. The agreement here, except for the case of $\mathrm{LC}_{3}$, is within the requirements of commercial accuracy. The lack of agreement in the case of $\mathrm{LC}_{3}$ is as yet unexplained, but in view of the excellent agreement for materials magnetically both harder and softer it seems probable that the difference is not due to the instrument but to some peculiarity of the specimen, such as nonhomogeneity.

In order to show how the accuracy obtained with this permeameter compares with the behavior of other instruments, the corrections to be applied to the various permeameters are plotted in Figs. 9 and Io. These figures are taken with slight modification from a paper by one of the present authors. The only change is the addition of the curves showing the corrections to the Fahy permeameter.

While the absolute method is the one most generally employed, it is of interest to note the accuracy that is obtainable when readings are taken by comparison with a standard. In Fig. II, the full-line curves represent the true normal induction, while the circles indicate readings on the Fahy permeameter by comparison with a standard. It will be seen that the agreement is exceedingly close, nowhere showing a difference as great as 5 per cent in the magnetizing force required for a given induction.

\section{UNCOMPENSATED DATA}

Fig. I 2 gives two induction curves as obtained by this apparatus. In one the compensation is made while in the second there is no compensation. A comparison of these data with the curves of 


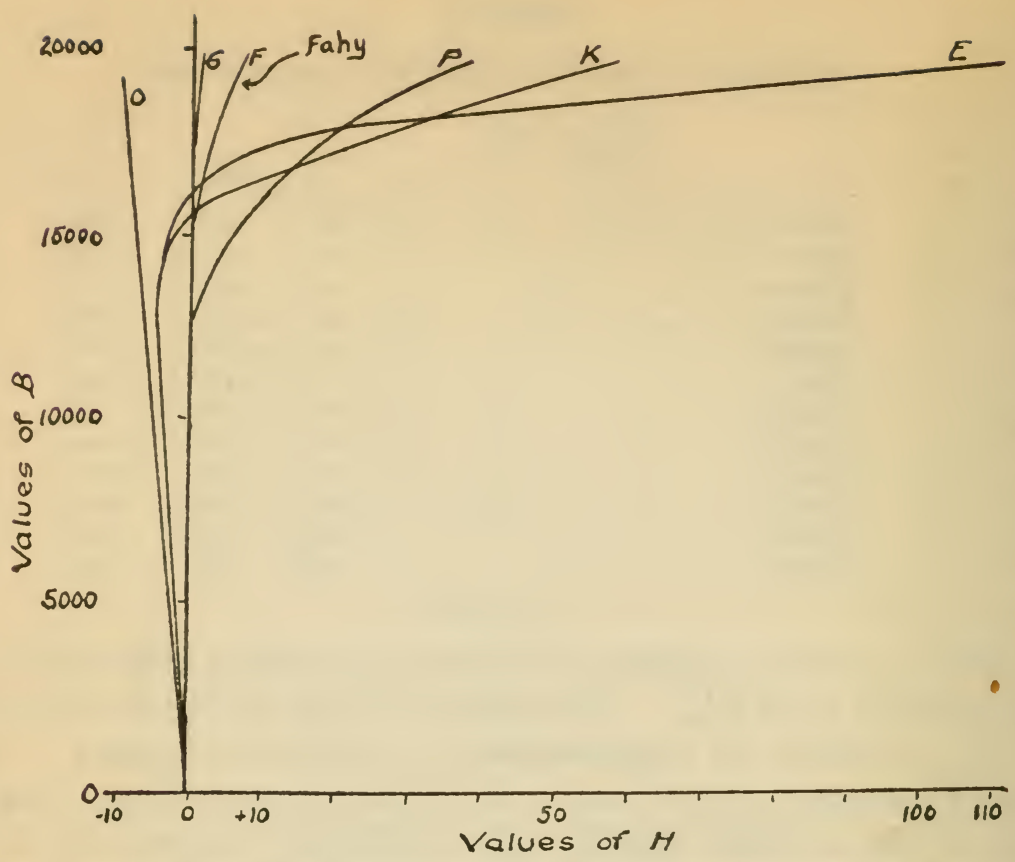

FIG. 9.-Shearing curves for a given quality of Norway iron as determined by various apparatus

$E$, Esterline; $P$, Picon; $K$, Koepsel; $G$ and $F$ from foreign research laboratories; $O$, a theoretical ovoid of 100 diameters

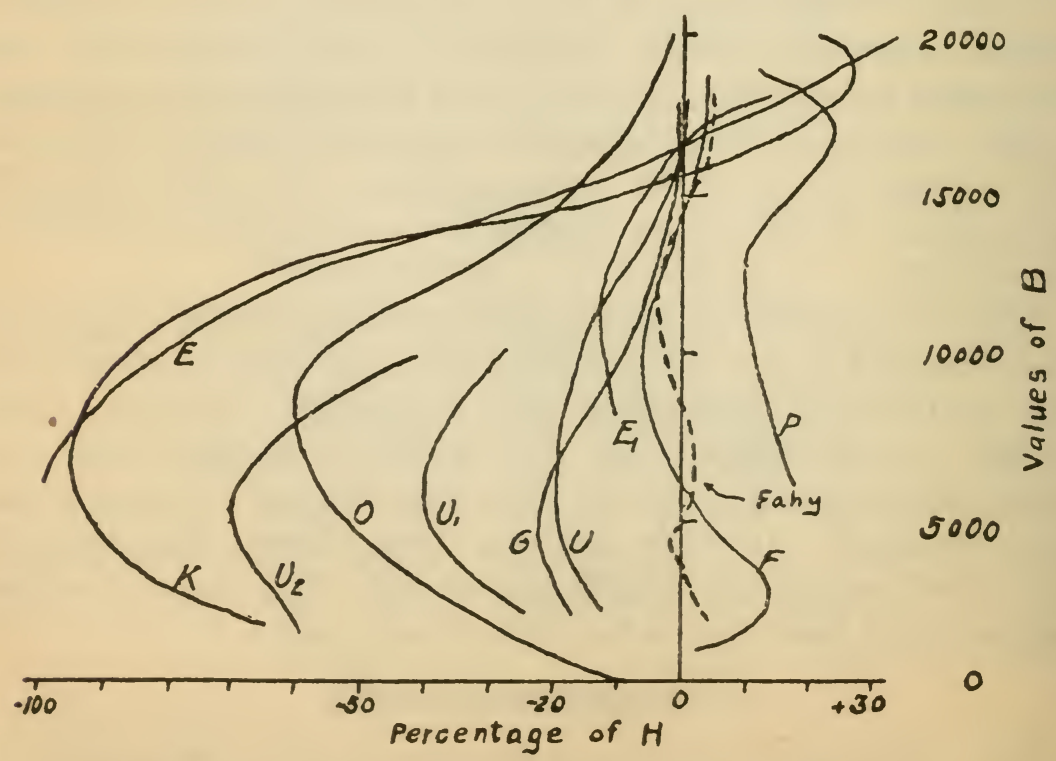

FIG. 10.-Showing the data of Fig. I8 on a percentage basis

$E$ and $E_{1}$ are the extreme curves from four Esterline permeameters; $U$ is from an uncompensated double yoke; $U_{1}$ is from a single yoke $(l=27.3 \mathrm{~cm}) ; U_{2}$ is from a single yoke $(l=16.8 \mathrm{~cm}) ; O, G, P . F$ are as in Fig. 18 


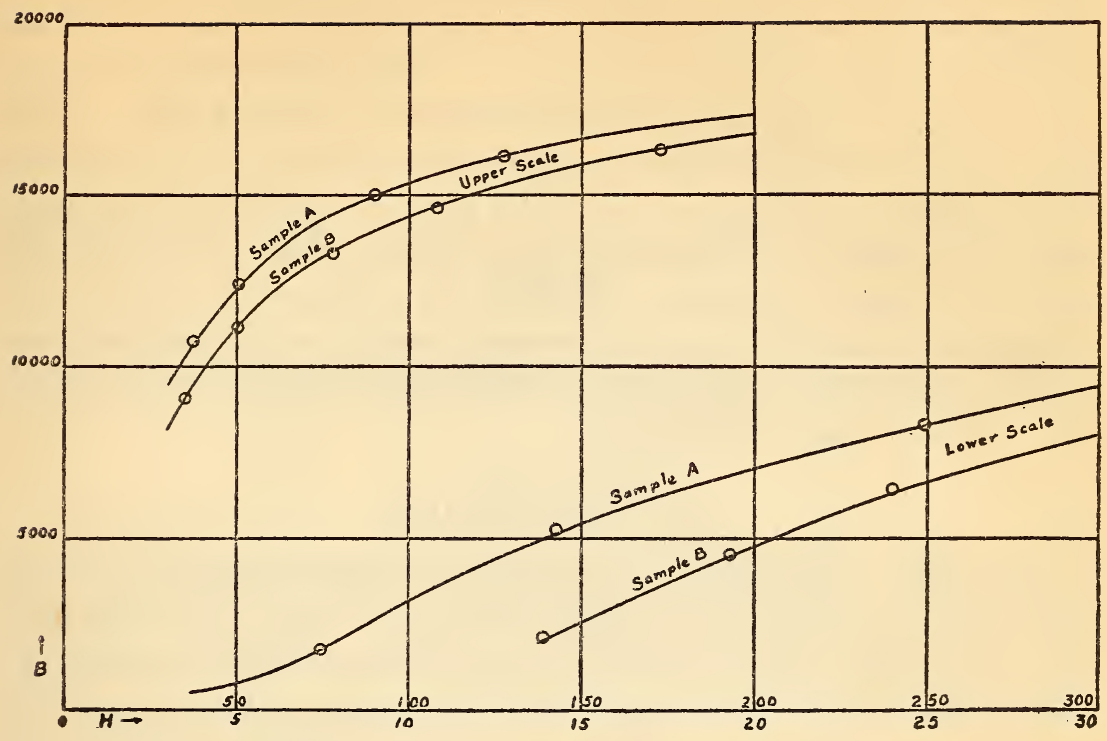

FIG. II.-Showing values obtained by the method of comparison

The solid curve represents the normal induction by the standard mcthod and the circles represent points taken by comparison with a standard bar

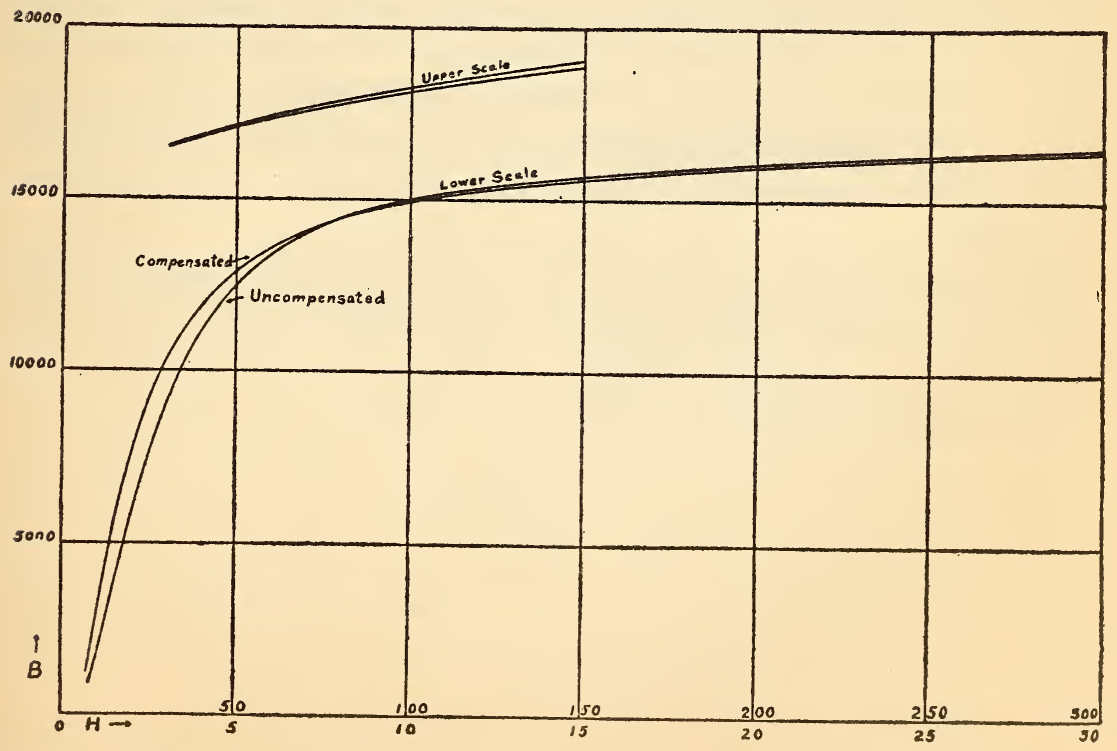

FIG. 12.- Showing normal induction curves for the same specimen with and without compensation 
Figs. 9 and ro will show that the error introduced by failure to compensate is no greater than the error existing in several of the types of permeameters now in use. This permeameter may be used without compensation in certain kinds of shop testing. Such tests may be desirable where comparative results only are desired. No erroneous conclusions as to the relative merits of two steels need be drawn. In materials very nearly alike the corrections would be nearly identical, so that the differences between the compensated and the uncompensated results would be the same.

The advantage, of course, in omitting the compensation lies in the greater speed of operation.

\section{CONCLUSION}

The Fahy permeameter represents a distinct advance in the measurement of magnetic characteristics of steel and other magnetic materials. In accuracy it far excels the direct-reading permeameters which have been rather commonly used both in this country and abroad. Normal induction measurements of solid bars show errors no greater than 5 per cent of the magnetizing force required for a given induction. The consistency of its readings taken at different times on the same specimen is so close that comparative results on similar materials can be obtained to a much higher degree of precision. Commercial materials, however, are seldom uniform enough to warrant better precision than 5 per cent. Hysteresis measurements are accurate within the limits of commercial requirements and the uniformity of commercial materials.

The apparatus has not as yet been adapted to the measurement of sheet materials but preliminary experiments indicate that such adaptation is entirely possible.

Washington, March 23, I917. 


\section{A P P E N D I X}

\section{DESCRIPTION AND OPERATION OF THE FAHY PERMEA- METER}

In view of the fact that a more detailed description of the permeameter and its mode of operation may be of some interest, it seems desirable to present more descriptive matter than properly belongs in the body of this paper.

\section{DESCRIPTION}

(a) The Magnetic Circuit.-Fig. I3 shows the permeameter in plan and elevation. $B$ represents the base of the apparatus upon which is mounted a magnetic core of $H$ shape, consisting of a crossbar $J$ formed at its ends with threaded portions, which screw into threaded sockets fashioned in the transverse core portions. The crossbar $J$ is divided midway between its ends into two sections separated by a small air gap, which may be closed to a greater or less extent by a screw piston $P$ of magnetic material, actuated through the knurled head $N$.

The ends of the transverse core portions form a part of each of the two paralle1 magnetic circuits and are adapted for bridging by specimens of magnetic material. In Fig. I3 a standard specimen $A$, the magnetic characteristics of which are known, bridges the core arms $Y$, and a test specimen $X$, the magnetic characteristics of which are to be determined, bridges the core arms $Y^{\prime}$. Clamps $O$ serve to hold the specimens in place. The ends of the core arms $Y$ and $Y^{\prime}$ are slotted to permit the insertion of bushings $W$, which vary in form according to the shape of the material bridging the core arms. The adjustable air gap in the crossbar $J$ is designed to create a demagnetizing force within the core itself, which may be varied to suit requirements. When the gap is open to its fullest extent, the magnetic poles created there when the magnetizing current is broken in the act of reversing the current are of material assistance in reducing the time constants of the magnetic circuits. This demagnetizing force may be adjusted to reduce to a negligible amount the magnetic field in the region occupied by the test specimen due to the residual properties of the core itself. Under this latter condition direct measurements of residual induction are simplified.

The magnetomotive force is applied in two sections, one over the crossbar $J$, by means of current in the magnetizing coil $M$ and the other distributed in equal parts over the core arms $Y Y^{\prime}$ by means of current in the compensating coils $C$. The currents in these two sections are independently adjustable. The test coils indicated by $D, D^{\prime}, S$, and $T$ are each of the same number of turns and placed as shown in the figure; $D$ and $D^{\prime}$ on opposite arms of the same transverse core portion and $S$ and $T$ uniformly wound on coil forms through which the standard and test specimens $A$ and $X$, respectively, may be inserted. A test coil $H$ of a relatively large number of turns is wound uniformly on the same form which carries the test coil $S$. The test coils $S$ and $T$ are of the same mean cross-sectional area.

Fig. I4 shows the flux paths within the magnetic core due to the magnetomotive forces generated by currents in the coils $M$ and $C$.

The magnetic field due to current in the magnetizing coil has the direction indicated by the arrows or the reverse according to the direction of the current. The field due to current in the compensating coils has the direction indicated by the dotted line, 
its direction at any time depending upon the direction of the current in the compensating coils. It will be seen that when current is flowing in both magnetizing and compensating coils, one magnetic circuit has the magnetomotive force due to its magnetizing coil augmented by the current in the compensating coils, while the other magnetic circuit has its magnetomotive force decreased by the same amount.
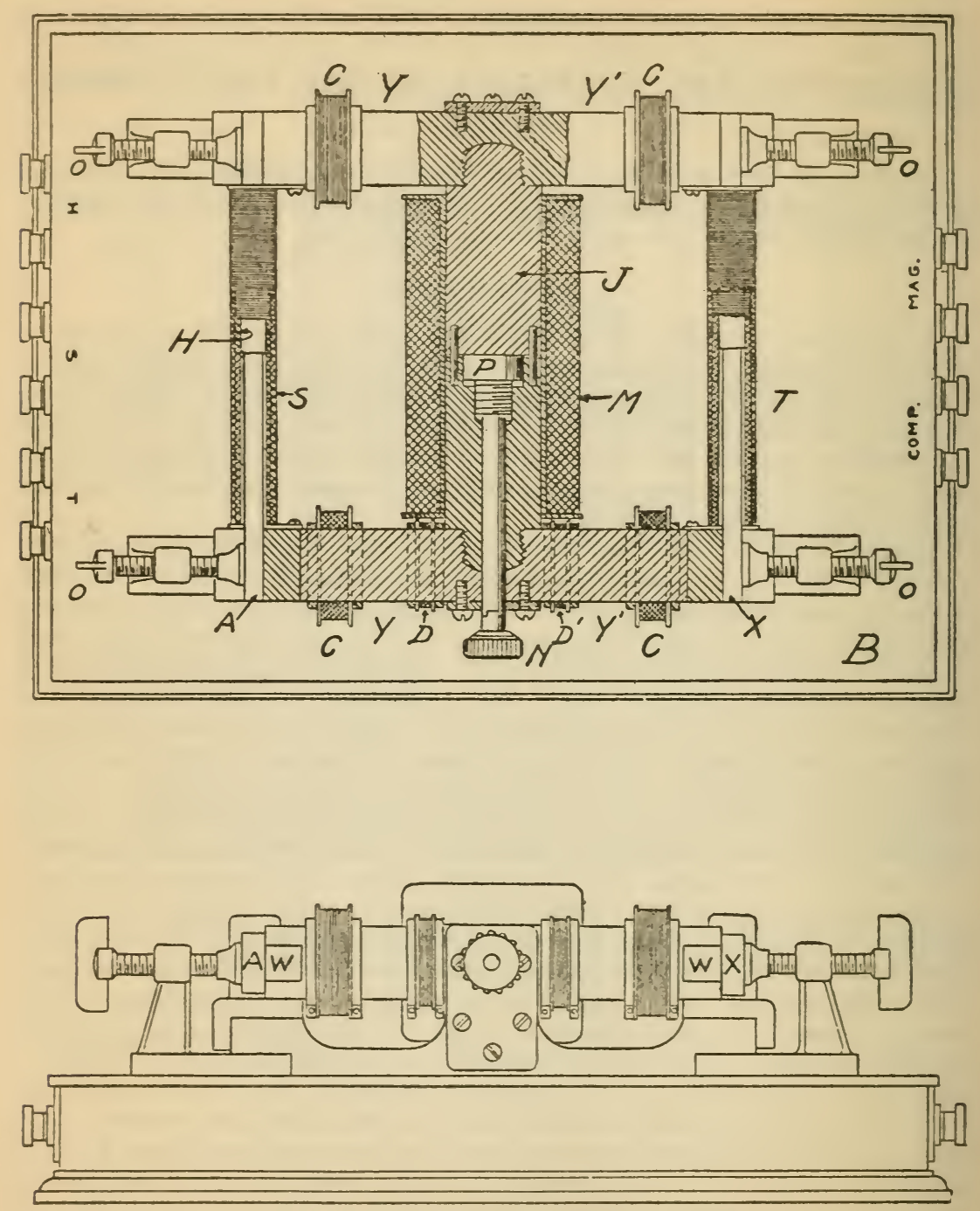

FIG. 13.-Diagram of the Fahy permeameter

It is obvious that by varying the current in the compensating coils $C C C \mathcal{C}$ the difference in fluxes linking the test coils $D^{\prime}$ and $T$ can be made equal to the difference in fluxes linking the test coils $D$ and $S$.

When the compensation is adjusted so that these flux differences are equal, the leakage flux through the air path which is in parallel with the path of the coil $T$ is equal to the leakage flux through the air path which is in parallel with the path of the coil $S$. Since these two leakage air paths are symmetrical and carry the same 
magnetic flux, the same difference of magnetic potential must exist between the ends of the path encircled by the coil $T$ that exists between the ends of the path encircled by the coil $S$. Consequently, the coil $H$, which is wound uniformly along the length of the coil $S$, and which may be used to measure the difference in magnetic potential over this region and hence of the mean magnetizing force for this region, gives also a measure of the mean magnetizing force along the path of the coil $T$ within which the test specimen lies.

(b) Internal Electrical Connections.-Fig. I4 shows also the internal electrical connections of the permeameter. The magnetizing and compensating coils are connected to the binding posts marked "Mag" and "Comp," respectively. The test coils $S, D$, $D^{\prime}$, and $T$ are permanently connected in series, taps being brought out to binding posts marked $S$ and $T$. This series connection is carried out in such a manner that

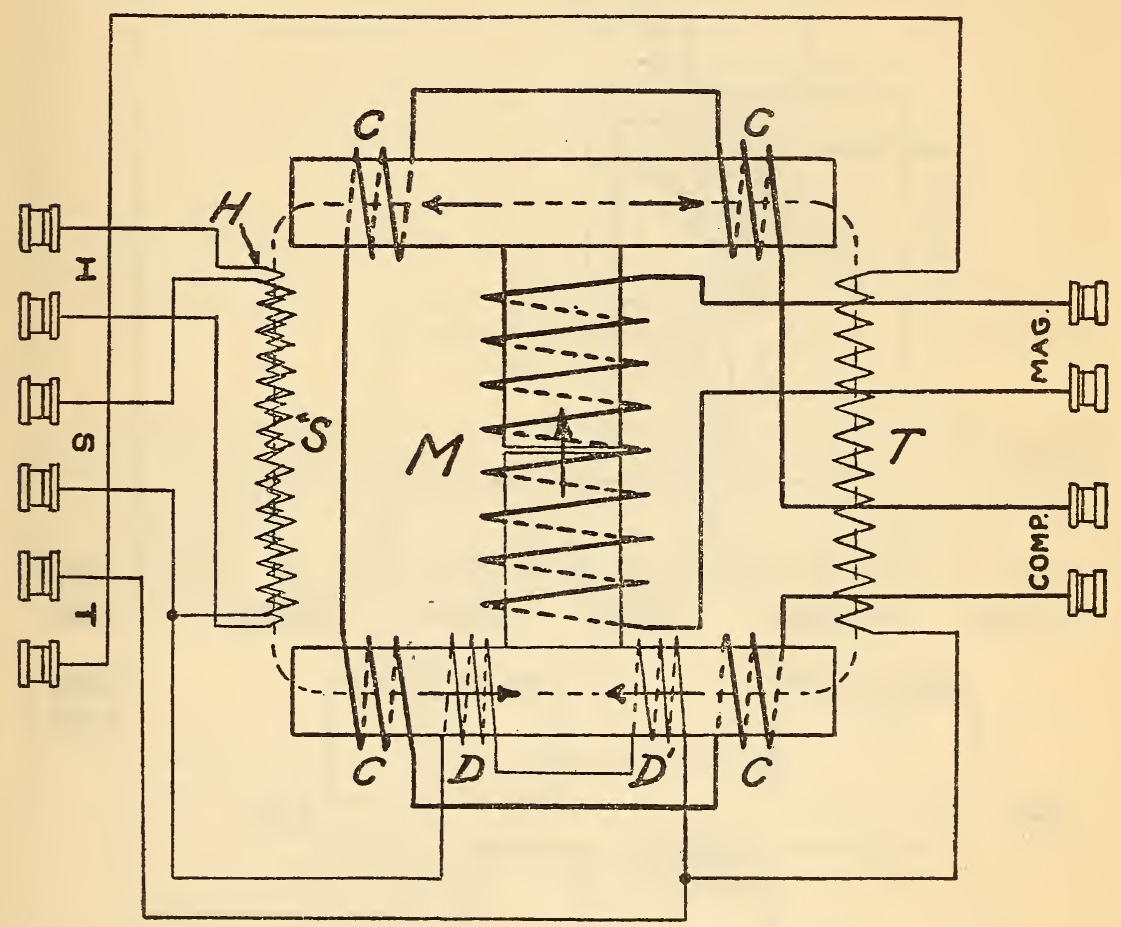

FIG. I4.-Internal electrical connections of the Fahy permeameter

upon reversal of the current in the magnetizing coil $M$ the integrated electromotive forcesinduced in the coils $S$ and $D^{\prime}$ act in the same direction and in opposition to the integrated electromotive forces simultaneousiy induced in the coils $D$ and $T$. Connection to the adjacent binding posts of the pairs marked $S$ and $T$ enables observation of the differential effect of the coils $D$ and $D^{\prime}$ to be made. The permeameter is initially adjusted, so that when no specimens are in the apparatus this differential effect is zero. Test coil $H$ is connected to the binding posts marked $H$.

(c) External Electrical Connections.-Fig. I5 shows the external electrical connections of the magnetizing, compensating, and test circuits. $M$ and $C$ refer to the magnetizing and compensating coils, respectively, and $M I$ is the primary of a mutual inductance; $S M$ and $S C$ are reversing switches for the corresponding circuits. When switch $S M I$ is thrown downward, $S M$ is the reversing switch for the mutual inductance. $R M$ and $R C$ are variable resistances in the magnetizing and compensating 


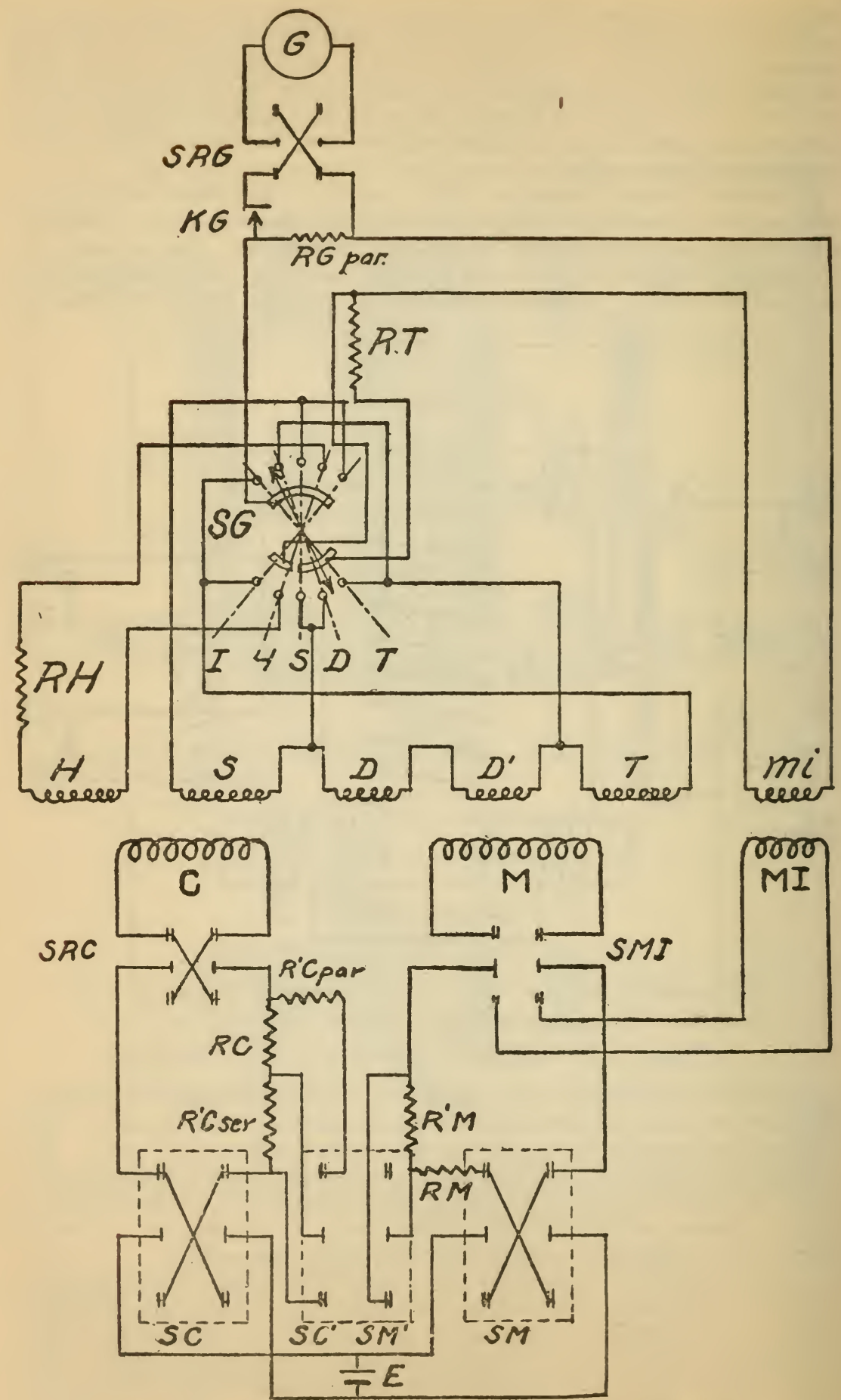

FIG. 15.-Complete electrical connections of the Fahy permeameter 
circuits, respectively. Switch $S M^{\prime}$ when thrown upward inserts the variable resistance $R^{\prime} M$ in series with the resistance $R M$. Switch $S C^{\prime}$ when thrown upward inserts the variable resistance $R^{\prime} C_{\text {ser }}$ in series with $R C$ and the variable resistance $R^{\prime} C_{p a r}$ in parallel with $R C$. The resistances $R^{\prime} C_{\text {ser }}, R^{\prime} C_{\text {par }}$, and $R^{\prime} M$ may each be made infinity or zero as may be required during the course of a test. The reversing switch SRC controls the initial direction of the current in the compensating coils $C$. $E$ represents a source of direct-current electromotive force.

The reversing switch $S M$, the combined switch $S C^{\prime}-S M^{\prime}$, and the reversing switch $S C$ may be operated either singly or in any combination by a specially designed handle which engages the individual switches by means of latchets. The normal position of these three switches is downward.

In the secondary circuits $D, D^{\prime}, S, T$, and $H$ refer to the test coils and $m i$ is the secondary of the mutual inductance. $G$ is a ballistic galvanometer and $S R G$ a switch which controls the direction of throw of the galvanometer. $R G_{\mathrm{par}}$ is a fixed resistance which is placed in parallel with the galvanometer when the key $K G$ is closed. $S G$ is a five-point-dial switch through which connections are made between the galvanometer and the following test coils: Switch $S G$ in position $I$ connects the galvanometer with coils $S, D, D^{\prime}$, and $T$ in series; in position $H$ with coil $H$; in position $S$ with coil $S$; in position $D$ with coils $D$ and $D^{\prime}$ in series; and in position $T$ with coil $T$.

$R T$ is an adjustable resistance in series with the galvanometer when the switch $R G$ is in the positions $S, D$, or $T$. $R H$ is an adjustable resistance in series with the galvanometer when the switch $R G$ is in the position $H$.

\section{CALIBRATION}

(a) Ballistic Galvanometer.-The galvanometer is calibrated by means of the mutual inductance $M I$, of fixed value, the secondary of which remains permanently in the galvanometer circuit. The reversal of a definite current in the primary of the mutual inductance produces a galvanometer deflection which is the same as that produced by the reversal of a definite number of gausses in the test specimen. The formula used in the calibration of the galvanometer is

where

$$
I=\frac{B N A}{M I 0^{8}}
$$

$I=$ current in amperes in primary of mutual inductance.

$B=$ gausses (flux per square centimeter).

$N=$ number of turns in test coil.

$A=$ area of test specimen in square centimeters.

$M=$ mutual inductance in henries.

Assuming, for example, the following values:

$$
\begin{aligned}
B & =10000 \\
N & =100 \\
A & =3 \\
M & =0.01
\end{aligned}
$$

then $I=3$ amperes. If it is desired to have $10 \mathrm{~cm}$ galvanometer deflection correspond to the reversal of ro ooo gausses, then with switch $S G$ on point $T$ the resistance $R T$ is adjusted until a reversal of 3 amperes in the primary of the mutual inductance produces Io $\mathrm{cm}$ deflection.

(b) Coil $H$.-The co. $H$ ss used to determine the magnetic potential difference existing between its ends when it encircles air only; that is, when no specimen is inserted within it. The average magnetic potential drop per unit length of the winding $H$ is equal to the average magnetizing force. The area turns, $N A$, of the coil are determined by measurements of the coil in a uniform field such as is produced by a long solenoid. The product $N A$ thus determined is subject to a correction if the 5 !) $467^{\circ}-18-9$ 
length of the coil $H$ is not the same as the free length of the test specimen between contacts at the pole faces. Experiment has shown that, for the instrument investigated, this correction is 3 per cent. This corrected value is used in calculating the current to be reversed in the primary of the mutual inductance in adjusting the sensitivity of the galvanometer to read magnetizing force. Adjustment for this purpose is made by means of the adjustable resistance $R H$.

\section{DETERMINATION OF NORMAL INDUCTION AND HYSTERESIS}

The permeameter can be used for either relative or absolute magnetic measurements. It can be used $(a)$ to determine the normal induction of a specimen of unknown magnetic characteristics by comparing it with a standard or known specimen, or $(b)$ to determine directly the normal induction and hysteresis of a specimen. The method of procedure depends to a considerable degree upon the accuracy desired. Where approximate values of permeability only are required, the procedure is extremely simple, and the accuracy is sufficiently high for many practical purposes.

(a) Normal Induction by Comparison.-A standard specimen A, the normal induction of which is known, is inserted in the standard coil $S$ and clamped in place. The unknown specimen $X$ is inserted in the test coil $T$ and clamped. Switch $S C^{\prime}-S M^{\prime}$ closed down and unlatched and remains so throughout the test; galvanometer switch $S G$ is placed on the point $S$; and switch $S . I I I$ is thrown downward. The galvanometer is then calibrated as already described, its sensitivity being adjusted by means of the resistance $R T$. Switch S.MI is then thrown up and the magnetizing coil $M$ energized. Both bars are then demagnetized by repeated reversals of a successively decreasing magnetizing current. This demagnetizing current is gradually reduced, by means of the resistance $R . M$, from a maximum value which brings the magnetization of the specimens well above the knees of their normal induction curves to a value lower than the lowest which is to be used. The frequency of reversal is about two per second. There should be no current in the $C$ coils during demagnetization. After demagnetization, the lowest magnetizing current to be used is set and reversed several times to bring the specimens to a magnetically cyclic state. Switch $S G$ is then placed on point $I$ and the magnetizing current is reversed. A deflection is generally observed which is due to the fact that the two sides of the magnetic circuit are not exactly symmetrical, due to difierent areas of the two specimens or differences in their magnetic characteristics. These differences cause different magnetomotive force drops in corresponding parts of the parallel magnetic circuits which must be compensated for in order to eliminate errors due to this cause. If the difference in the fluxes linking the test coils $D^{\prime}$ and $T$ is less than the flux difference between $D$ and $S$, a deflection of the galvanometer is observed which may be reduced to zero by means of current in the compensating coils $C$. Stwitch $S R C$ is closed in such a direction that when switches $S C$ and $S M$ are closed in the same direction the magnetomotive force in the magnetic circuit, which includes the test specimen, is augmented over that due to the main solenoid alone, while the magnetomotive force in the circuit including the standard specimen is decreased. The magnitude of this compensating magnetomotive force is adjusted by means of the resistance $R C$ until upon simultaneous reversal of $S C$ and $S M$ the residual deflection of the galvanometer is zero. This adjustment is to be made for each point on the normal induction curve. The reversals of the magnetizing current during the adjustment are generally sufficient to reduce the specimen to a cyclic condition. When compensation is complete, switch $S G$ is placed on point $S$, and the deflection due to the reversal of flux in the coil $S$ is read upon reversal of switch S.M. SG is then placed on point $T$, and the deflection due to the reversal of flux in the coil $T$ is read upon a second reversal of switch S.M.

Since the coils $S$ and $T$ have areas greater than the specimens $A$ and $X$, the observed inductions are too great. The correction to be subtracted is $\frac{a-A}{A} H$ where $a$ 
is the area of the test coil, $A$ the cross-sectional area of the specimen, and $H$ the magnetizing force. From the normal induction curve for the standard specimen, the $H$ corresponding to the observed induction is determined and the correction applied giving the true induction from which the true $H$ can be derived. A similar "air correction" is to be applied to the induction observed in the coil $T$. When the specimen $X$ is of the same area as $A$, the true induction of $X$ thus obtained may be plotted against the value of $H$ as taken from the curve of the standard specimen. When the area of $X$ is different from $A$, since the galvanometer is calibrated for $A$, the true induction for $X$ is

$$
B_{\text {true }}=\frac{A}{A^{\prime}}\left(B_{\text {obs }}-\frac{a-A^{\prime}}{A^{\prime}} H\right)
$$

where $A^{\prime}$ is the area of specimen $X$. Other points on the induction curve are obtained in a similar manner. It is not necessary to repeat the demagnetization in the determination of successive points at magnetizing forces greater than the preceding.

If approximate values will be satisfactory, the above procedure may be simplified by omitting the compensations. In this case switch $S R C$ remains open throughout the test. The errors will depend upon the differences existing between the permeabilities and areas of the test specimen and of the standard.

When it is inconvenient to insert the test specimen in a test coil, a reading of the induction through the specimen may be made with switch $S G$ on the point $D$. The galvanometer then reads the difference between the fluxes through the core arms $Y$ and $Y^{\prime}$. This differential flux, when algebraically added to the induction observed through the coil $S$, gives the induction in the specimen $X$. No air correction is necessary for the test specimen reading, but correction is made for differences in area of the test and standard specimens. When practicable it is best to have the standard and test specimens of equal areas.

(b) Normal induction by Absoluie Method.-Absolute measurements of normal induction are made without the use of a standard bar. Compensation for unequal magnetomotive force drops in the two magnetic circuits should be made except when approximate results only are desired. With material of low permeability, results without compensation are, in general, fairly satisfactory. Normal induction readings of high permeability material are unsatisfactory unless compensation is used.

The adjustment of the compensation in the absolute measurement of normal induction is similar to that already described. The galvanometer resistances are adjusted as described under "galvanometer adjustment." The measurements of the magnetizing force and the induction are made by reversing simultaneously the switches $S C$ and $S M$. The ballistic deflection of the galvanometer, when $S G$ is on the point $H$, gives directly the magnetizing force acting on the specimen $X$. The induction of the specimen $X$ is read when $S G$ is on $T$ as before.

(c) Hysteresis.-Measurement of hysteresis is made without the use of a standard bar, the magnetizing force being read from coil $H$ and the induction from coil $T$.

The determination of a hysteresis loop can perhaps be best explained with references to Fig. I6. When the specimen $X$ has been magnetized to a desired degree and the cyclic state is established, its condition is represented by the point $A$, which is called the tip of the loop. The magnetizing force is then $O_{1}$ and the induction is $O X$. If the magnetizing force is reversed, the specimen is carried along the magnetic path represented by $A E K$ to the point $K$, where the magnetizing force and induction are each of the same magnitude as at $A$, but opposite in direction. The change in induction, therefore, is twice the induction at the tip.

Instead of reversing the magnetizing force we may reduce it to the value represented by the point $C$. The reduced magnetizing force is then $\mathrm{O}_{2}$ and the corresponding induction $O D$. The change in induction, which is the quantity actually measured by the test coil encircling the specimen, is that represented by $X D$. If the apparatus is calibrated to read induction, in taking normal induction by reversals 
the reading of the test coil is to be multiplied by two in each case to give the true cliange in induction. The value of the induction at any point on the loop is the induction at the tip minus the change in induction. Points at the left of the $O B$ axis are obtained by reversing the direction of the magnetizing force at the same time that it is reduced in value. If the change in induction is greater than the induction at the tip, it indicates that the flux has changed in sign as well as in magnitude as at the point $G$.

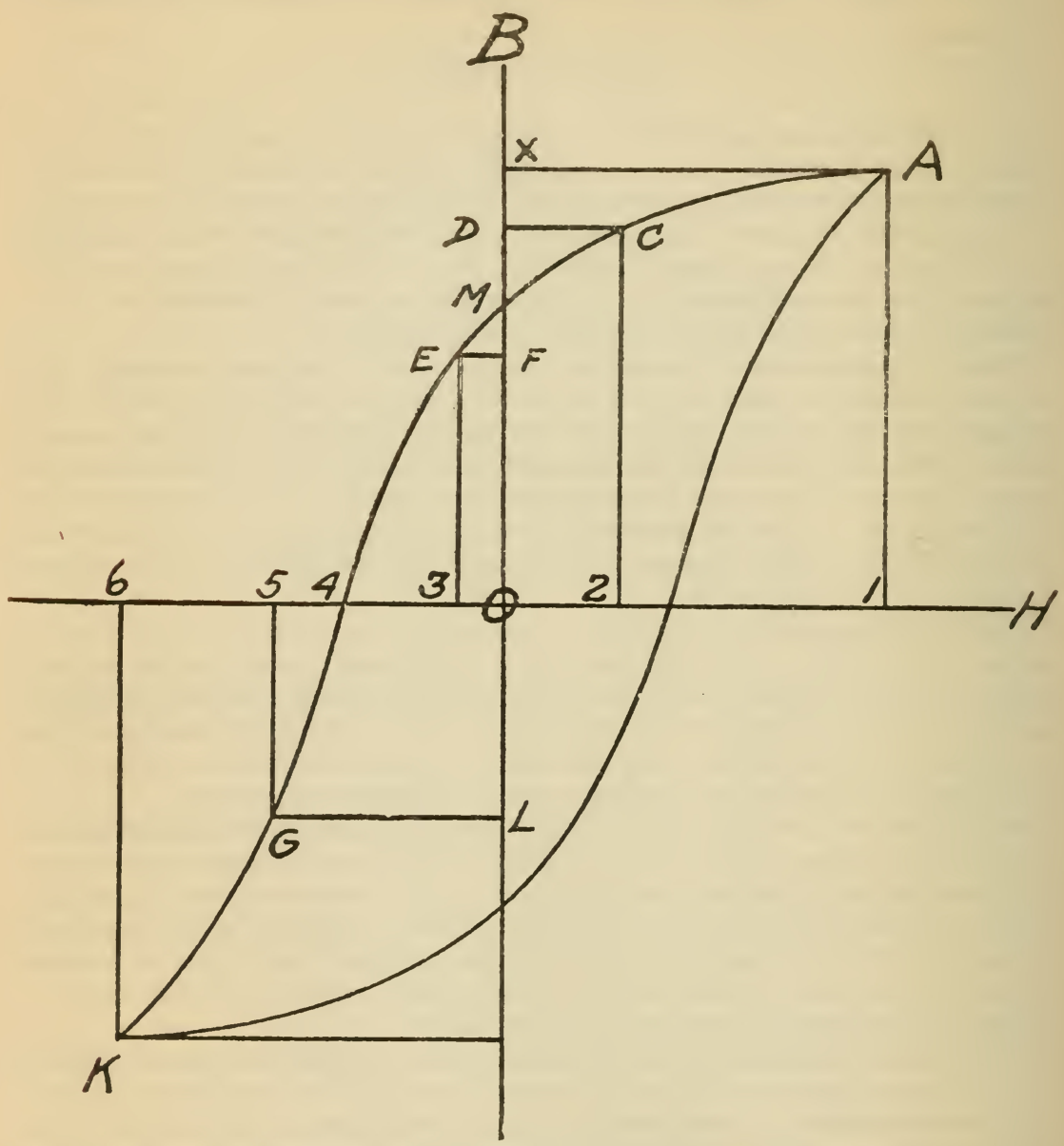

FIG. I6.-Typical hysteresis loop

In practice the tip of the loop is set either at a defirite induction or at the induction corresponding to a definite magnetizing force. Switches $S M, S C^{\prime}-S M^{\prime}$, and $S C$ are closed downward and compensation effected for the required tip as in $3 . R^{\prime} \mathrm{C}_{\mathrm{par}}$ is increased to infinity and $S G$ placed on the point $I . S C^{\prime}-S M^{\prime}$ is thrown upward and the galvanometer deflection observed. If the resistance $R M^{\prime}$ is properly chosen, the magnetizing current will be decreased so that the magnetizing force is, say, $O-2$, Fig. I6. Note that no currents are reversed in these operations. If the galvanometer deflection observed on throwing $S C^{\prime}-S M^{\prime}$ upward is not zero, compensation must be adjusted. $S C^{\prime}-S M^{\prime}$ is closed downward and $S M$ and $S C$ reversed several times to 
regain the cyclic condition, being closed finally downward. $R^{\prime} C_{\text {ser }}$ is adjusted and $S C^{\prime}-S M^{\prime}$ again closed upward. If $R^{\prime} C$ series is properly adjusted, the residual galvanometer deflection will be zero. If there is still a residual galvanometer deflection, bring the induction in the specimen to a cyclic state as before, and try again with a new adjustment of $R^{\prime} C_{\mathrm{ser}}$. When compensation for the reduction of the induction from the tip is effected, $S G$ is closed on the point $T, S C^{\prime}-S M^{\prime}$ is closed downward, and $S M$ and $S C$ reversed to regain the cyclic condition, being closed finally downward. Then, closing $S C^{\prime}-S M^{\prime}$ upward, the galvanometer deflection is noted. The observed induction corresponding to the reduced magnetizing force is equal to the induction at the tip minus twice the change in induction observed. Closing $S G$ on $H$, and restoring the cyclic condition in the usual monner, observe the change in magnetizing force on closing $S C^{\prime}-S M^{\prime}$ upward. The observed magnetizing force is equal to the magnetizing force at the tip minus twice the change in magnetizing force observed.

The observed magnetizing force is the true magnetizing force as the galvanometer is calibrated for the area of the $H$ coil. An air correction is applied to the observed induction, as in the case of normal induction by the formula

$$
\begin{aligned}
& B_{\text {true }}=B_{\text {obs }}+K\left(H_{1}-H_{2}\right) \\
& \text { where } K=\frac{a-A}{A} \text { as before } \\
& \text { and } H_{1}=\text { magnetizing force at the tip } \\
& \text { and } H_{2}=\text { magnetizing force at the lower point. }
\end{aligned}
$$

If the magnetizing force is reduced to a point near the axis, but not reversed, it may be necessary to reverse the compensation at the same time it is reduced. This is accomplished by reversing $S C$ at the same time as $S C^{\prime}-S M^{\prime}$ is operated. Again, it may be necessary both to reverse and increase the compensation. This is accomplished by reducing $R^{\prime} C_{\text {ser }}$ to zero and adjusting $R^{\prime} C_{\text {par }}$, switch $S C$ being reversed at the same time that $S C^{\prime}-S M^{\prime}$ is operated. To pass from the tip to negative values of the magnetizing force, as for instance to $O_{-3}$, Fig. I6, $S M$ is reversed at the same time as the other switches are operated.

For many purposes, as for instance in the determination of the constants of magnet steel, it is necessary to determine only the residual induction and coercive force of a specimen. These quantities are represented by $O M$ and $O_{4}$, respectively, in Fig. I6. This is accomplished by so adjusting the resistances in the manner described above that, for residual induction, the change in magnetizing force indicates that the magnetizing force at the lower point is zero, and, for coercive force, the change in induction is such that the true induction at the lower point is zero. The corresponding values of induction and magnetizing force determine the points desired.

\section{MANIPULATION}

During the course of a complete magnetic test where direct measurements are obtained, the individual switches may take the following positions:

Position I. Switches $S M, S C^{\prime}-S M^{\prime}$, and $S C$ are down and the corresponding electrical connections are as shown in Fig. I7.

Position 2. Switches $S M$ and $S C$ are up. Switch $S C^{\prime}-S M^{\prime}$ is down. Circuits are the same as $I$, with currents reversed.

Position 3. $R^{\prime} C_{\text {par }}$ placed on infinity point. Switch $S C^{\prime}-S M^{\prime}$ is up. Switches $S M$ and $S C$ are down. Circuits as shown in Fig. I8.

Position $4 . R^{\prime} C_{\text {ser }}$ placed on zero point. Switch $S C^{\prime}-S M^{\prime}$ is up. Switcles $S M$ and $S C$ are down. Circuits as shown in Fig. Ig.

Position 5. $R^{\prime} C_{\text {par }}$ placed on infinity point. Switches $S M$ and $S C^{\prime}-S M^{\prime}$ are up. Switch $S C$ is down. Circuits as shown in Fig. 20. 


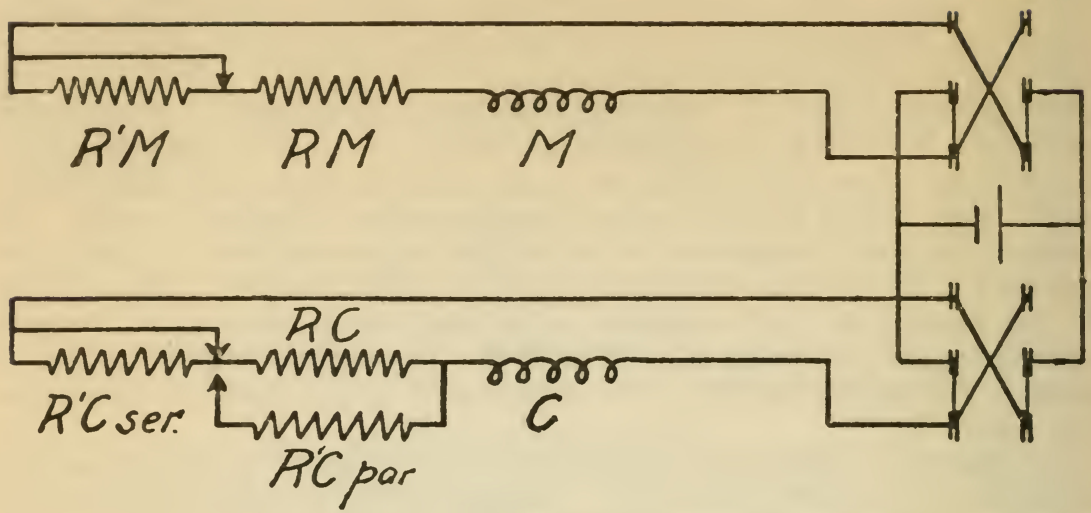

FIG. I7.-Electrical connections when switches are in position I

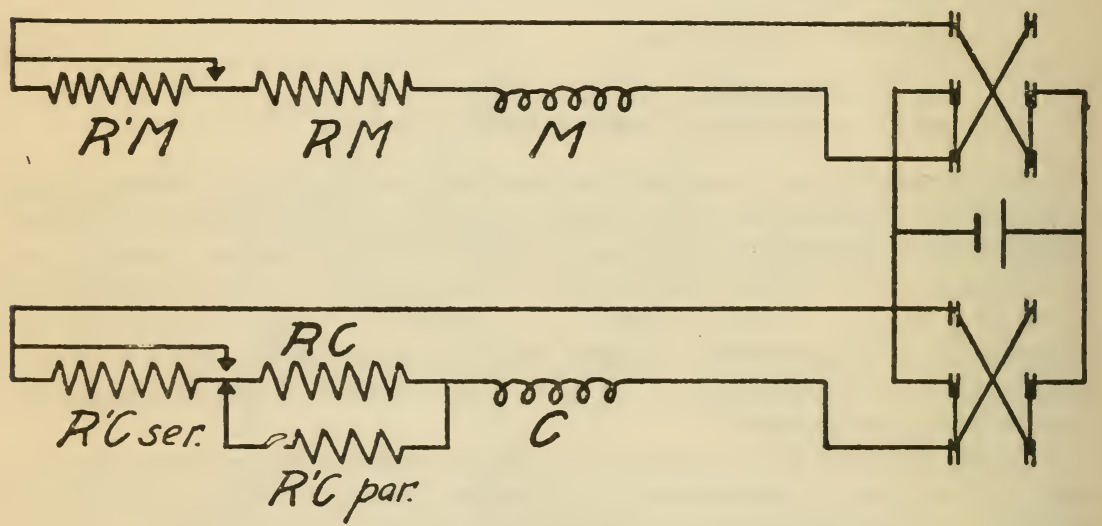

FIG. IS.-Electrical connections when switches are in position 3

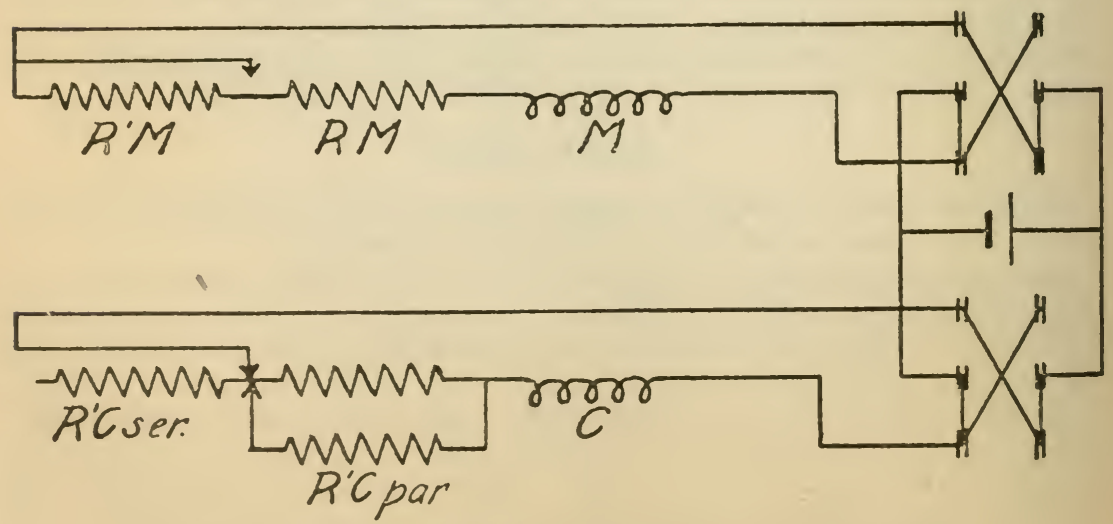

Fig. I9.-Electrical connections when switches are in position 4 


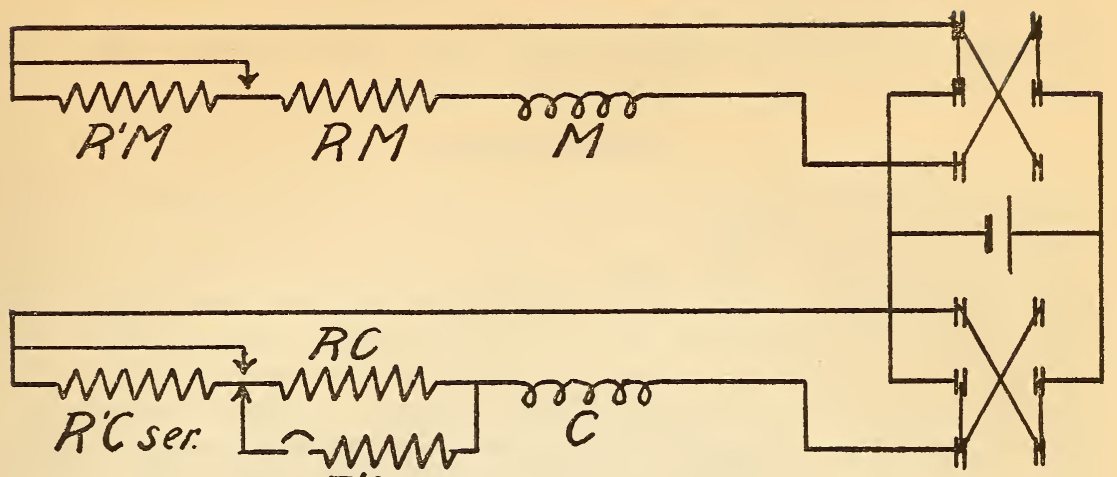

RiC par.

FIG. 20.-Electrical connections when switches are in position 5

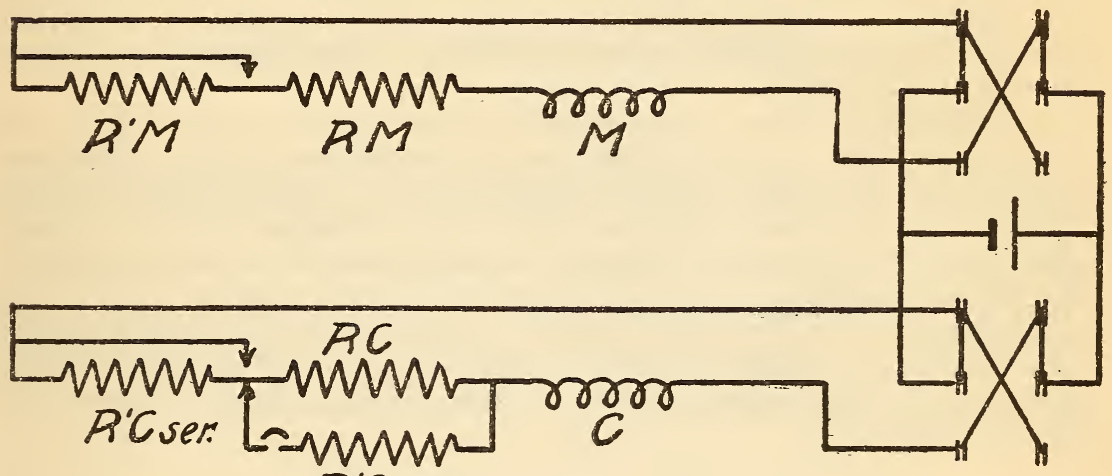
$P^{\prime} C$ par.

FIG. 21.-Electrical connections when switches are in position 6

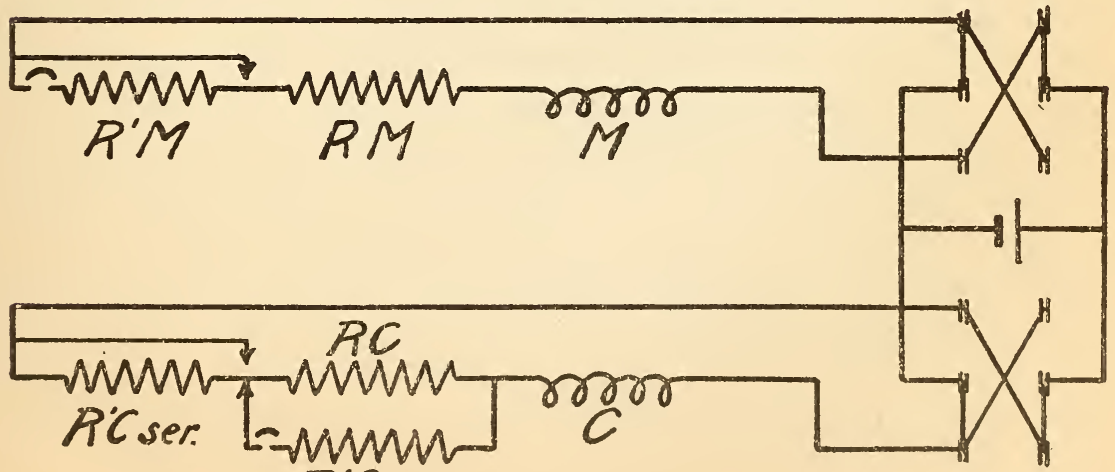
P'C por

FIG. 22.-Electrical connections when switches are in position 7 
Position 6. $R^{\prime} C_{\text {par }}^{\prime}$ placed on infinity point. Switches $S M, S C^{\prime}-S M^{\prime}$, and $S C$ are up. Circuits as shown in Fig. 21 .

Position 7. $R^{\prime} M$ and $R^{\prime} C_{\text {par }}$ placed on infinity point. Switches $S M$ and $S C^{\prime}-S M^{\prime}$ are up. Switch $S C$ is down. Circuits as shown in Fig. 22.

\section{PRECAUTIONS}

In order to obtain the highest precision and accuracy from this apparatus, certain things should be kept in mind.

(a) Magnetic Contacts.-The magnetic contact between the specimen and the pole faces should be reasonably good. Poor contact may result from irregularities in the surface of the specimen, such as small elevations and depressions. The specimen may be covered with scale or rust, and thus produce the equivalent of an actual separation of the specimen from the pole face. A warped specimen may also give poor contact. Since the two pole faces lie in the same plane, if the specimen is bowed the corresponding contact surface reduces to a line contact. Diffculties of these kinds may occur in castings, hot-rolled bars, and in bars that have been heat treated. Machined specimens are generally free from contact troubles.

(b) Position of Specimen.-The specimen should be placed against the pole faces, so that there is no portion projecting beyond the test-coil pole faces. Specimens should be of sufficient length to span the pole faces. Longer lengths may be used, but are not recommended.

(c) External Ficld.-Since this apparatus has a large external magnetic field, care must be taken to see that this field does not exert an influence upon any other part of the circuit. The mutual inductance must be placed at some distance from the magnetic circuit and in such a position that no lines of magnetic flux link the secondary coil. The galvanometer should be separated from the magnetic circuit, so that there is no influence exerted either upon the permanent magnet or the coil of the galvanometer. Finally, all the leads of the secondary circuits should be brought near to each other or twisted, so as to eliminate the possibility of induced electromotive forces in these parts of the circuits. This arrangement of the apparatus is made once for all. 